MARCELO WEBER

Dor Muscular e Temperatura Muscular:

Estudo termográfico longitudinal

São Paulo 


\section{MARCELO WEBER}

Dor Muscular e Temperatura Muscular:

\section{Estudo termográfico longitudinal}

\section{Versão Original}

Tese apresentada à Faculdade de Odontologia da Universidade de São Paulo, pelo Programa de Pós-graduação em Odontologia, para obter o título de Doutor em Ciências.

Área de concentração: Diagnóstico Bucal

Orientadora: Profa. Dra. Emiko Saito Arita 
Autorizo a reprodução e divulgação total ou parcial deste trabalho, por qualquer meio convencional ou eletrônico, para fins de estudo e pesquisa, desde que citada a fonte.

Catalogação da Publicação

Serviço de Documentação Odontológica

Faculdade de Odontologia da Universidade de São Paulo

Weber, Marcelo.

Dor muscular e temperatura muscular: estudo termográfico longitudinal / Marcelo Weber ; orientador Emiko Saito Arita. -- São Paulo, 2016.

58 p. : fig., tab., graf.; $30 \mathrm{~cm}$.

Tese (Doutorado) -- Programa de Pós-Graduação em Odontologia. Área de concentração: Diagnóstico Bucal. -- Faculdade de Odontologia da Universidade de São Paulo.

Versão original.

1. Disfunção temporomandibular. 2. Termografia. 3. Mialgia. 4. Temperatura muscular. I. Arita, Emiko Saito. II. Título. 
Weber M. Dor muscular e temperatura muscular: estudo termográfico longitudinal Tese apresentada à Faculdade de Odontologia da Universidade de São Paulo para obtenção do título de Doutor em Ciências.

Aprovada em: / 2016

\section{Banca Examinadora}

Prof(a). Dr. (a). Instituição:

Julgamento: Assinatura:

Prof(a). Dr.(a). Instituição:

Julgamento: Assinatura:

Prof(a). Dr.(a). Instituição:

Julgamento: Assinatura:

Prof(a). Dr. (a). Instituição:

Julgamento: Assinatura:

Prof(a). Dr. (a). Instituição:

Julgamento: Assinatura: 
Aos meus pais, Maria Consuelo e Heloar por todo apoio e carinho, mas acima de tudo por terem me ensinado a importância de estudar.

Aos meus irmãos Wagner, Walkiria e Teodosia pelo apoio que sempre me deram.

A minha amada esposa Kennia e a meus filhos, Artur e Alexandre por seu amor incondicional e seu apoio nos momentos mais difíceis. 


\section{AGRADECIMENTOS}

A minha orientadora, Professora Emiko Saito Arita, pelo acolhimento na pós-graduação em Diagnóstico Bucal, pela sua paciência e sabedoria nos momentos mais difíceis desta jornada. A você, professora, por ter me incentivado e apoiado a concluir esta tese no Canadá, através de um Doutorado Sanduíche.

Ao Professor Dr. Jeferson de Oliveira por seu apoio e confiança

À Professora Dra. Ana Miriam Velly da McGill University por ter me acolhido no Jewish General Hospital em Montreal para me co-orientar neste trabalho.

Ao Professor Dr. Mervyn Gornitsky da McGill University de Montreal pelo acolhimento e pelos conhecimentos transmitidos.

Ao Professor Dr. Claudio Costa por seus ensinamentos e amizade.

Aos voluntários que se interessaram e colaboraram acreditando e se submetendo a esta pesquisa.

Aos meus colegas da pós-graduação em Radiologia da FOUSP, pela amizade e troca de conhecimentos que realizamos ao longo do tempo.

A todos os meus mestres que me impulsionaram e orientaram ao longo de minha vida. 
" Com efeito, ao falar do caráter de um homem, não dizemos que ele é sábio ou que possui entendimento, mas que é calmo ou temperante. No entanto, louvamos também o sábio, referindo-se aos hábitos; a aos hábitos dignos de louvor chamamos virtudes"

Autor: Aristóteles

Livro: Ética à Nicômaco 
Weber M. Dor muscular e temperatura muscular: estudo termográfico longitudinal [tese]. São Paulo: Universidade de São Paulo, Faculdade de Odontologia; 2016.

\section{RESUMO}

Embora as causas de DTM tenham sido muito estudadas e discutidas na literatura atual, a associação entre a dor muscular e sua temperatura não está totalmente clara. Para esta investigação, 40 pacientes com dor muscular foram encaminhados da clínica odontológica e foram examinados. Um total de 31 pacientes foram diagnosticados com dor miofascial no musculo masseter pelo RDC e foram incluídos neste estudo. O musculo masseter no lado com dor foi anestesiado e foi comparado ao lado oposto ao longo do tempo. $\mathrm{Na}$ análise estatística de comparação, foi encontrada associação entre o aumento de temperatura e a diminuição da dor relatada. Possíveis fatores de confusão, como tempo da dor crônica, idade, índice de massa corpórea, pontos de incapacidade, ICD, pior dor sentida nos últimos meses e dor media nos últimos meses foram levados em consideração e foram estatisticamente analisados e o único fator que mostrou estatisticamente correlação com a diminuição da dor foi o fator tempo. Conclusão: existe uma correlação negativa entre o aumento de temperatura e a diminuição da dor.

Palavras-chave: Disfunções temporomandibulares. Termografia. Dor muscular. Temperatura muscular. 
Weber M. Muscle Pain and Muscle Temperature : A longitudinal thermographic study [doctoral thesis]. São Paulo: Universidade de São Paulo, Faculdade de Odontologia; 2016.

\section{ABSTRACT}

Although, TMD causes have been widely studied in the last years, the association between muscle pain and temperature remains unclear. For this investigation, 40 muscle pain patients were referred from dental clinic and were examined. A total of 31 patients were diagnosed with masseter myofascial pain by RDC criteria and were included in this study. Masseter muscle was blocked in the pain side and was compared among the time to opposite side. In the matching statistics association analysis, it was found association between temperature increase and related pain decrease. Possible confounders (time of chronic pain, age, Body Mass Index, ICD, incapacity points, worst pain in the last six months, average pain in last six month) were took in consideration and only time since the pain started seems to be related to decrease in pain. Conclusion: there is a negative association between muscle pain and muscle temperature.

Keywords: Temporomandibular disorders. Thermography. Muscle pain. Muscle temperature. Myofascial pain. 


\section{LISTA DE TABELAS}

Tabela 5.1- Associação de fatores e Dor.

.33

Tabela 5.2 - Associação de fatores e temperatura do lado com dor 34 


\section{LISTA DE FIGURAS}

Figura 4.1 - Cone encaixado no termógrafo com abertura focal de $1,2 \mathrm{~cm} \ldots \ldots \ldots \ldots \ldots \ldots . . \ldots . . .24$

Figura 4.2- Perfuração no cone para inserção do sensor de temperatura.....................24

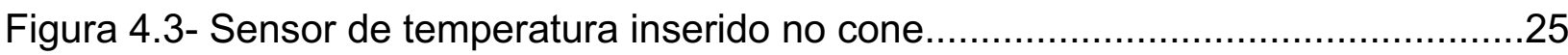

Figura 4.4- Termograma do musculo masseter............................................26

Figura 4.5- Bloqueio anestésico do musculo masseter..........................................27

Figura 5.1- Variação da temperatura ao logo do tempo.........................................30

Figura 5.2 - Variação da dor ao logo do tempo..................................................31

Figura 6.1- Teste pareado para variação da temperatura.......................................36

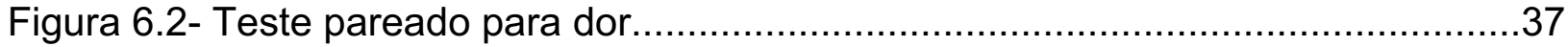

Figura 6.3- Teste pareado de temperatura dos 31 indivíduos antes da anestesia.........39

Figura 6.4- Teste pareado de temperatura dos 31 indivíduos depois da anestesia......40

Figura 6.5 - Teste pareado de temperatura dos 31 indivíduos depois da anestesia.......41 


\section{LISTA DE ABREVIATURAS E SIGLAS}

DCA Pontos de incapacidade

DTM Disfunções Temporomandibulares

ICD Intensidade característica da dor

IMC IÍndice de massa corpórea

MFP Paciente com dor miofascial

MW Marcelo Weber

P10MA Dor 10 minutos depois do bloqueio anestésico

P2MA Dor 2 minutos depois do bloqueio anestésico

P2MB Dor 2 minutos antes do bloqueio anestésico

RDC Randomized Clinical Trial

TCS10MA Temperatura do lado controle 10 minutos depois do bloqueio anestésico

TCS2MA Temperatura do lado controle 2 minutos depois do bloqueio anestésico

TCS2MB Temperatura do lado controle 2 minutos antes do bloqueio anestésico

TPS10MA Temperatura do lado com dor 10 minutos depois do bloqueio anestésico

TPS2MA Temperatura do lado com dor 2 minutos depois do bloqueio anestésico

TPS2MB Temperatura do lado com dor 2 minutos antes do bloqueio anestésico

VAS Escala visual analógica

PGM Pontos-gatilho latentes miofasciais

PPT L Limiar de dor a pressão

MPS Síndrome dolorosa miofascial

FMS Fibromialgia

PG Pontos-gatilho 


\section{LISTA DE SÍMBOLOS}

$\sigma$

$\mathrm{mm}$

$\mathrm{cm}$

${ }^{\circ} \mathrm{C}$
Desvio padrão

Milímetros

Centímetros

graus Celsius 


\section{SUMÁRIO}

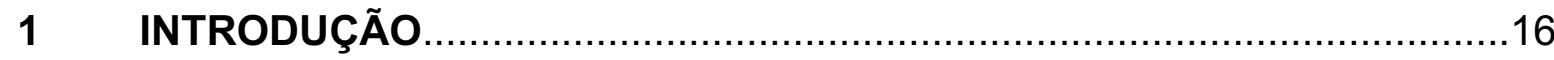

2 REVISÃO DA LITERATURA

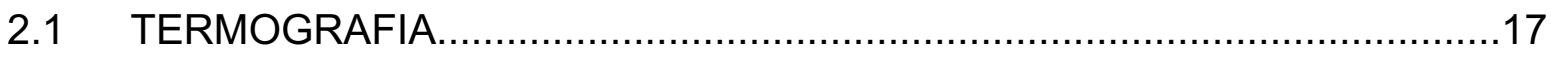

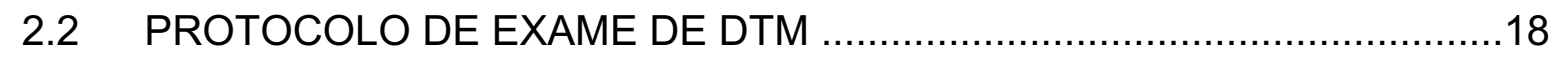

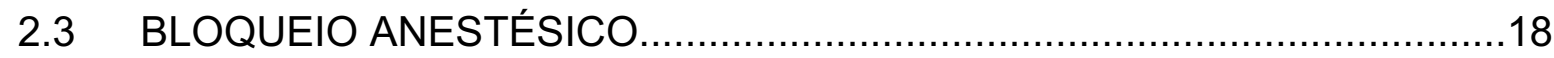

3 PROPOSIÇÃO

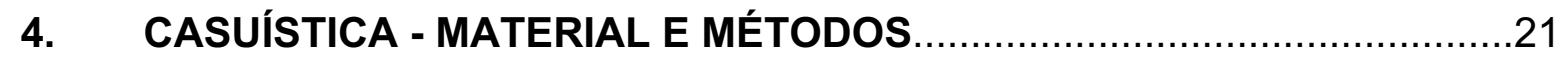

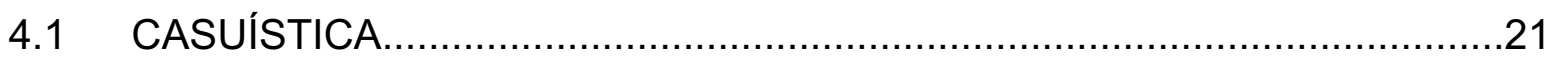

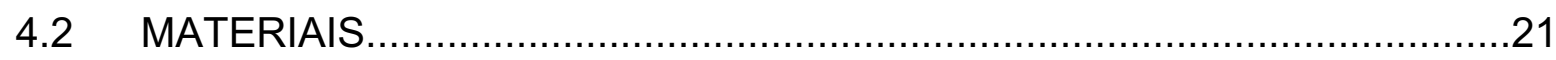

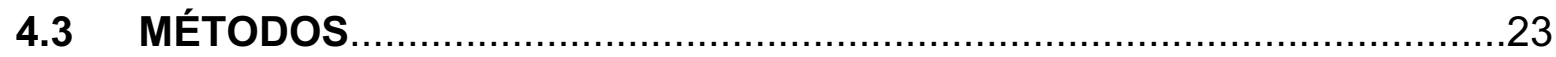

4.3.1 SELEÇÃO DAS AMOSTRAS E CRITÉRIOS DE

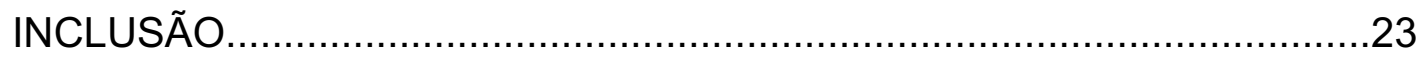

4.3.2 PROTOCOLO PARA O EXAME DE TERMOGRAFIA ............................23

4.4 PROTOCOLO PARA O BLOQUEIO ANESTÉSICO ..................................26

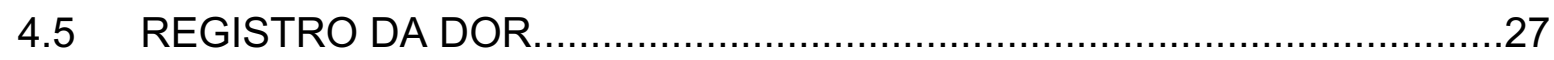

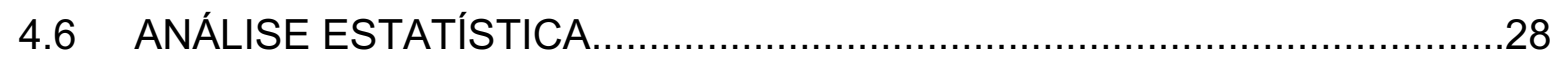

$5 \quad$ RESULTADOS

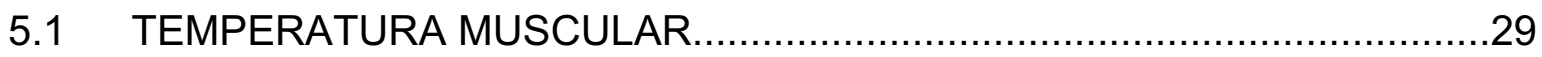

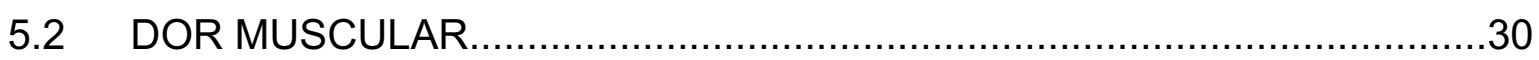

5.3 ANÁLISE ESTATÍSTICA LONGITUDINAL DOS TEMPOS 1, 2 E 3 QUANTO À DOR RELATADA................................................................

5.4 ANÁLISE ESTATÍSTICA LONGITUDINAL DOS TEMPOS 1, 2 E 3 QUANTO À TEMPERATURA NO LADO COM DOR.............................32

5.5 ANÁLISE ESTATÍSTICA LONGITUDINAL DOS TEMPOS 1, 2 E 3 QUANTO À TEMPERATURA NO LADO COM DOR...

5.6 ANÁLISE ESTATÍSTICA LONGITUDINAL ENTRE OS FATORES QUE PODERIAM INFLUENCIAR NA DIMINUIÇÃO DA DOR.

5.7 ANÁLISE ESTATÍSTICA LONGITUDINAL ENTRE OS FATORES QUE PODERIAM INFLUENCIAR A TEMPERATURA NO LADO COM DOR..

6 DISCUSSÃO .36 


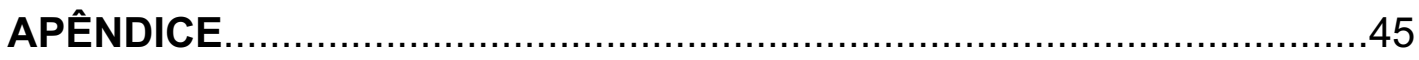

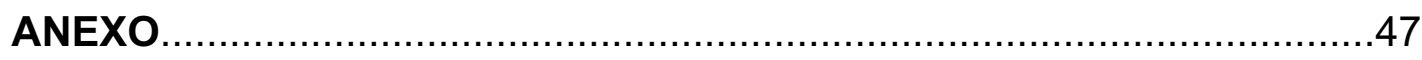




\section{INTRODUÇÃO}

Pacientes tem relatado empiricamente, uma associação entre a diminuição da temperatura ambiente e o aumento ou inicio de dores musculares faciais.

A aplicação de calor e frio em músculos com dor miofascial, faz parte do protocolo de tratamento das Disfunções Temporomandibulares, mas como a temperatura se relaciona com a dor muscular não se apresenta claro na literatura.

O diagnóstico de anormalidades neurológicas e musculoesqueléticas por termografia baseia-se na assimetria térmica local entre os músculos de lados opostos. Termogramas de indivíduos normais são caracterizadas por temperaturas simétricas, portanto, assimetrias de temperatura sugerem a presença de disfunções temporomandibulares ou outras formas de dor facial, segundo Haddad et al. (2014).

Muitas técnicas têm sido aplicadas no tratamento das Disfunções Temporomandibulares, como bloqueio anestésico, uso de placas oclusais, tens, microcorrente, laserterapia, medicamentos e termoterapia com aplicação de calor e frio. Porem, muitas dúvidas existem quanto ao tipo de termoterapia, se é melhor aplicar frio, calor ou ambos combinados. Por isso como as alterações de temperatura estão ligadas a diminuição ou aumento da dor precisam ser melhor esclarecidas.

Este trabalho tem a intenção de investigar, através da termografia, a associação entre a dor muscular e a temperatura muscular, através da indução da alteração da dor muscular em um curto espaço de tempo e observar se a diminuição da dor é acompanhada por um aumento da temperatura do musculo masseter. 


\section{REVISÃO DA LITERATURA}

\subsection{TERMOGRAFIA}

O uso de termografia infravermelha em Odontologia foi mínimo até a década de 1990, porque a tecnologia era insuficiente e não permitia dados precisos. No entanto, com o desenvolvimento dos sistemas atuais, é possível obter imagens térmicas digitas com alta definição e boa precisão Biagioni et al. (1996).

Zhang et al. (2009) estudaram a mudança do fluxo de sangue em pacientes com dor muscular e presença de pontos-gatilho por termografia e concluíram que havia uma diminuição na temperatura muscular por atividade aumentada vasoconstritora simpática.

Dibai Filho et al. (2012) analisaram a temperatura do músculo trapézio utilizando a termografia em mulheres com e sem dor. Trinta e seis estudantes foram classificados de acordo com o NDI (índice de incapacidade do pescoço), em 2 grupos: 18 pacientes com dor e 18 indivíduos sem dor cervical. Todos os voluntários foram submetidos a termografia e nenhuma mudança de temperatura foi observada entre os dois grupos, bem como qualquer assimetria termográfica foi encontrada entre 0 músculo trapézio do lado direito e lado esquerdo.

Morimoto et al. (1991) estudaram a mudança de temperatura do músculo masseter em indivíduos saudáveis, depois de mascar chiclete e observaram um aumento na temperatura de 1,4 graus e que a temperatura diminuiu após a cessação de mastigar, mas manteve-se superior, mesmo depois de 30 minutos.

Bartuzi et al. (2012) encontraram uma correlação entre dados EMG e termografia. Indivíduos saudáveis foram submetidos a uma mastigação de baixa intensidade e a atividade muscular foi monitorada usando eletromiografia e termografia antes, durante e após a mastigação e com atividade muscular aumentada. Também observaram temperatura muscular aumentada.

Hong e Hsueh (1996) estudaram a mudança de temperatura dos músculos faciais após a injeção de glutamato e concluíram que a atividade de vasoconstrição simpática é exclusivamente devida à estimulação de pontos gatilho, porque após a injeção de glutamato não houve nenhuma diminuição na temperatura. 
Ford e Ford (1997) estudaram as imagens térmicas de 993 pacientes com enxaqueca com e sem aura, cefaleia crônica diária, cefaleia pós-traumática e uma variedade de outras enxaquecas. 69,9\% de 993 indivíduos tinham enxaqueca sem aura e destes, 593 ou 85,4\% termografia anormal. 20,3\% de 993 indivíduos tiveram enxaqueca com aura e destes $89.1 \%$ apresentaram termografia anormal. Dos indivíduos estudados, $85,7 \%$ com cluster e $85,7 \%$ dos indivíduos com cefaleia póstraumática apresentaram termografia anormal.

Pogrel et al. (1996) avaliaram 22 pacientes com dor muscular cervical através de termografia e concluíram que esta pode ser útil no diagnóstico de desordens temporomandibulares.

Haddad et al. (2014) investigaram pacientes com dor miofascial e 23 mulheres (10 laserterapia voluntários de DTM e 13 controles) foram recrutadas. A sensibilidade e a especificidade da avaliação termográfica para a região de masseter foram de $70 \%$ e $73 \%$, respetivamente e para a região do músculo temporal anterior foi de $80 \%$ e $62 \%$, respetivamente.

\subsection{PROTOCOLO DE EXAME DE DTM}

De acordo com Ohrbach et al. (2010), Schiffman et al. (2010a), Schiffman et al. (2010b), Truelove et al. ( 2010), o RDC/TMD eixo I DTM para diagnóstico de DTM possui sensibilidade $\geq 0,70$ e especificidade $\geq 0,95$. A validade do alvo foi obtida somente para dor miofascial sem diferenciação entre abertura normal e limitada. Revisão dos algoritmos diagnósticos atuais eixo I DTM é necessária para melhorar a sua validade.

\subsection{BLOQUEIO ANESTÉSICO}

De acordo com Venancio et al. (2009), injeções de ponto gatilho com diferentes soluções têm sido estudadas, principalmente no que diz respeito ao gerenciamento da dor de pacientes de dor miofascial (MFP). No entanto, poucos estudos têm 
analisado o seu efeito em uma população de cefaleia crônica com MFP associada. Eles investigaram as injeções de ponto de gatilho usando toxina botulínica, lidocaína e injeções com agulha seca para o tratamento de dor local e tratamento associado de dor de cabeça. Quarenta e cinco pacientes de dor miofascial com dores de cabeça que poderiam ser reproduzidos ativando o ponto gatilho de pelo menos um ponto, foram separados aleatoriamente em um dos três grupos: G1, seco-acupuntura, G2, lidocaína 0,25\%, 0,25\% e a toxina botulínica G3 e foram avaliados durante um período de 12 semanas. Foram avaliados os níveis de intensidade de dor, frequência e duração, sensibilidade após infiltração local, tempo de obtenção e duração de alívio e o uso de medicação para terapia de apoio. Estatisticamente, todos os grupos mostraram resultados favoráveis para os requisitos avaliados $(p<o u=0,05)$, exceto para o uso de medicação de apoio e a sensibilidade no local de injeção (G3 mostrou melhores resultados). Considerando seu custo reduzido, concluíram que lidocaína pode ser adotada como uma substância de escolha e a toxina botulínica deve ser reservada para casos refratários, em que os efeitos esperados não poderiam ser alcançados, e o uso de uma terapia mais cara seria obrigatório.

Frost et al. (1980) em um estudo duplo-cego investigaram 28 pacientes com dores musculares agudas, com aplicação de quatro injeções locais de mepivacaína 0,5\%, e 25 pacientes com o mesmo tipo de dor receberam injeções locais de uma quantidade equivalente de soro fisiológico. O grupo recebendo soro tende a ter mais alívio da dor, especialmente após a primeira injeção. Assim, os resultados mostram que o alívio da dor não é devido apenas ao anestésico local.

Hong e Hsueh (1996) observaram que a injeção de ponto gatilho é um valioso procedimento para alívio da dor em pacientes com dor miofascial e fibromialgia. 


\section{PROPOSIÇÃO}

O objetivo desta investigação é verificar se existe associação entre a temperatura do músculo com dor miofascial tratado com bloqueio anestésico e a diminuição da dor. 


\section{CASUÍSTICA - MATERIAL E MÉTODOS}

\subsection{CASUÍSTICA}

Neste estudo longitudinal de 12 minutos, inicialmente, 40 pacientes de DTM foram referidos da clínica odontológica da FOUSP com dor muscular no musculo masseter como principal queixa. Nove deles foram descartados porque tinham dor em outros músculos associada. Decidimos exclui-los porque diferentes músculos possuem diferentes temperaturas e isto poderia induzir a um possível viés na pesquisa. Um total de 31 pacientes (78\%) com dor miofascial do musculo masseter foram diagnosticados e incluídos no estudo. O diagnóstico foi baseado no critério RDC/DTM e foi realizado por um dentista calibrado (MW).

\subsection{MATERIAIS}

Para a realização desse trabalho, foi utilizado:

- Material de equipamento de proteção individual (EPI): gorro, máscara, luva e avental;

- Lápis dermatográfico;

- Lenço umedecido para remoção das marcações feitas com lápis dermatográfico;

- Fichas clínicas:

Questionário 1 - RDC em Português

Questionário 2 - Complementar ao RDC

Ficha de exame termográfico

Termo de Consentimento Livre e Esclarecido (TCLE)

Escala visual analógica de dor (VAS), diagrama de dor e registro dos achados obtidos pela palpação dos músculos estudados bilateralmente: masseter inserção;

- Higrômetro e termômetro INSTRUTEMP ITHT 2250 para registrar a umidade relativa e temperatura do ar do ambiente;

- Câmera Flir I3 com certificado de calibração; 
- Softwares FLIR Reporter® 8.5 - SP3 Professional Edition (FLIR Systems@ Inc., EUA) e Flir QuickReport® 1.2 SP1 (FLIR Systems@ Inc., EUA);

- Cone de $20 \mathrm{~cm}$ com abertura focal de 1,2 cm;

- Agulha curta para bloqueio anestésico;

- Carpule com refluxo;

- Mepivacaína a $2 \%$ sem vasoconstritor.

\subsection{MÉTODOS}

\subsubsection{Seleção das amostras e critérios de inclusão e exclusão}

Foram selecionados 31 pacientes diagnosticados com dor miofascial no musculo masseter. $O$ diagnóstico foi feito com base em 2 questionários e exame clínico. Protocolo de exame do RDC/TMD e um questionário complementar foram aplicados (Schiffman et al., 2010a; Schiffman et al., 2010b).

Fatores que poderiam influenciar os resultados térmicos, como sendo em tratamento para DTM, dor de dente, neuralgia do trigêmeo, febre, alterações sistêmicas (cetoacidose diabética, hipoglicemia, hipotireoidismo, hipertensão, doenças respiratórias, artrite reumatoide, no dia do exame e gravidez), presença de lesões de pele ou qualquer processo inflamatório (por exemplo, acne, hematomas, etc.) nos músculos para ser avaliada também foi utilizado como critério de exclusão.

Foram também excluídos da amostra, os voluntários com histórico de alergia a anestésicos.

\subsubsection{Protocolo para o exame de termografia}

Os voluntários selecionados foram posicionados em uma cadeira odontológica em uma sala com de temperatura e umidade controlados. 
O termógrafo recebeu um dispositivo cônico de $20 \mathrm{~cm}$ de altura e abertura focal de $2 \mathrm{~mm}$ (Figura 4.1). A abertura do cone foi direcionada para a porção do músculo masseter marcada com lápis dermatográfico de ambos os lados sem tocar a pele do paciente, pois isso poderia aquecer o cone e alterar os resultados. O dispositivo cônico encaixado no termógrafo permitiu padronizar a distância e a área estudadas através do termógrafo.

Figura 4.1 - Cone encaixado no termógrafo com abertura focal de $1,2 \mathrm{~cm}$

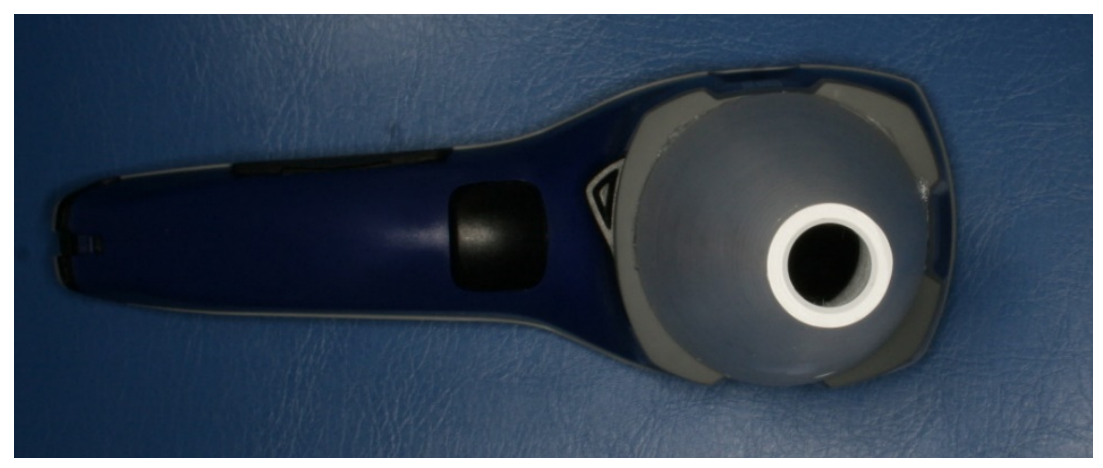

Este cone foi fabricado em PVC e foi perfurado para receber a ponta do sensor de temperatura do termômetro científico da Instrutemp (Figura 4.2). 
Figura 4.2 - Perfuração no cone para inserção do sensor de temperatura

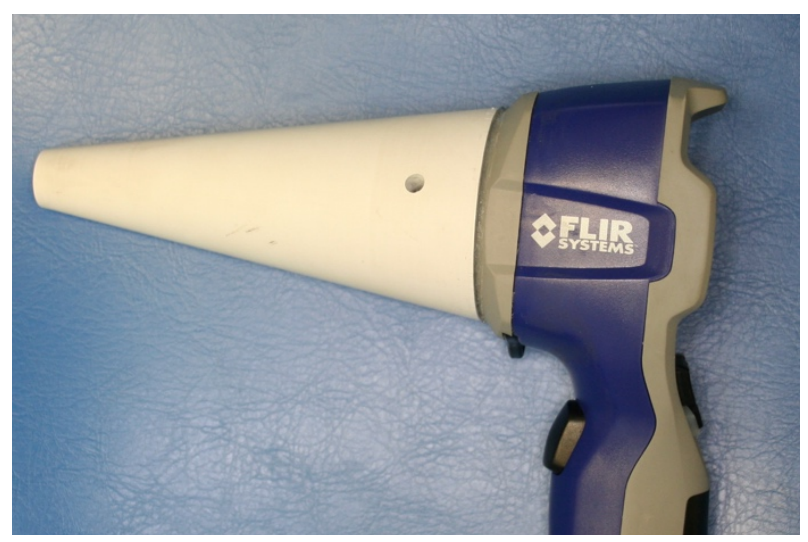

Sensor de Temperatura inserido para monitoramento da temperatura interna do cone e evitar que alterações de temperatura do cone pudessem interferir nos resultados da pesquisa (Figura 4.2). O cone, além de padronizar a distância de $20 \mathrm{~cm}$ para tomada do termograma, evitou correntes de ar que pudessem interferir na temperatura da superfície da pele e ainda padronizou o tamanho da área de estudo, que no caso, foi de $20 \mathrm{~cm}$.

Figura 4.3- Sensor de temperatura inserido no cone

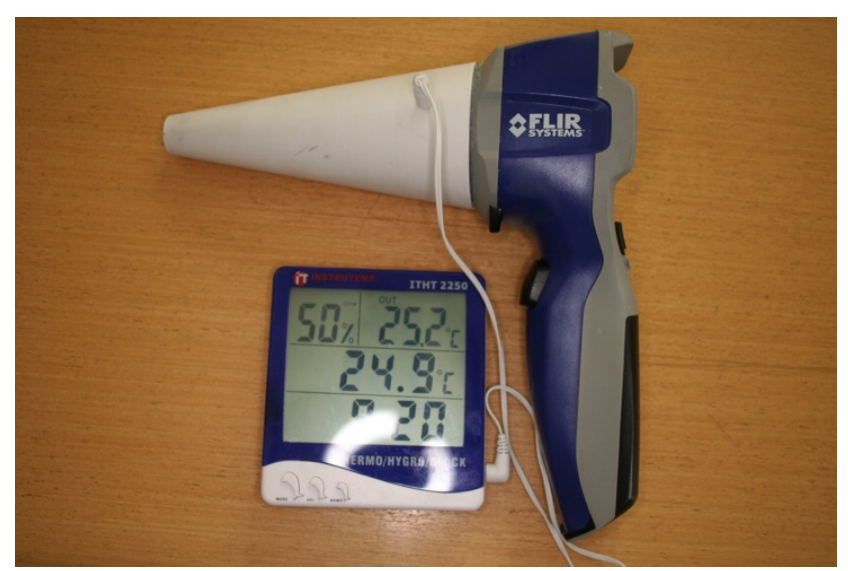

O termômetro mostra simultaneamente a temperatura interna do cone (Figura 4.3) e a temperatura da sala em tempo real. 
O aparelho Instrutemp mostra também a umidade em tempo real do ambiente. Os dados referentes a temperatura ambiente, temperatura do cone e umidade do ar, juntamente com a distância focal de $20 \mathrm{~cm}$ do cone são utilizados para calibrar o valor da temperatura do músculo.

Os termogramas foram obtidos 2 minutos antes do bloqueio anestésico, 2 minutos após o bloqueio e 10 minutos após bloqueio anestésico.

Os termogramas foram transferidos do termógrafo para o computador para serem calibrados e ajustados. A área de $1,2 \mathrm{~cm}$ de diâmetro, correspondente a abertura focal do cone foi delimitada (Figura 4.4) e os termogramas obtidos foram calibrados, conforme distancia focal de $20 \mathrm{~cm}$, temperatura e umidade registrados, através do software fornecido pelo fabricante FLIR e que acompanha o aparelho (Figura 4.4).

Em termografia, as áreas com temperatura mais alta são denominadas hiperradiantes e as áreas com temperatura mais baixa são denominadas hiporradiantes. 


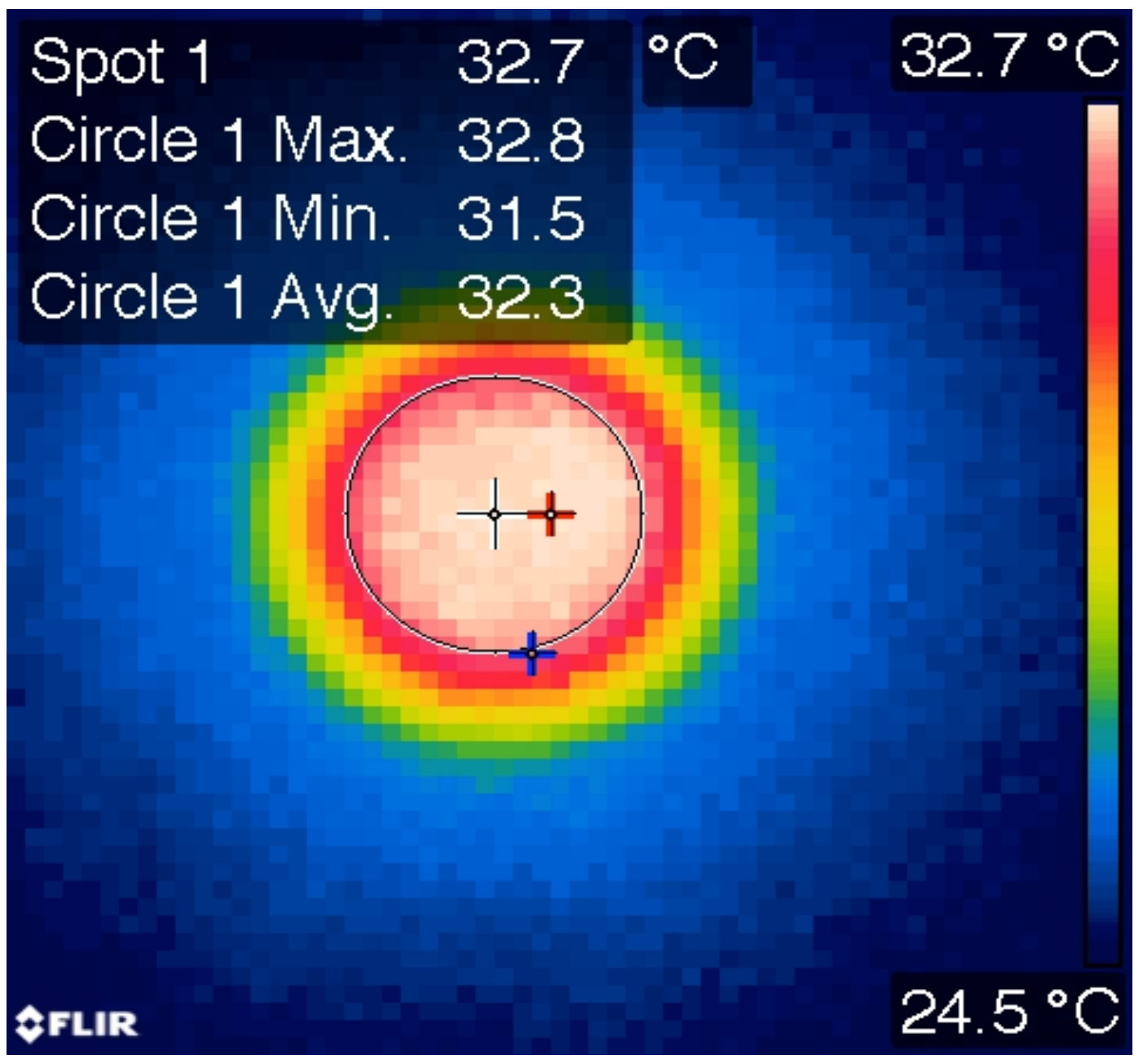

\subsection{PROTOCOLO PARA O BLOQUEIO ANESTÉSICO}

Os trinta e um pacientes incluídos no estudo receberam tratamento com anestésico local, mepivacaína 3\% sem vasoconstritor. O anestésico foi aplicado na porção profunda do musculo masseter, tomando-se o cuidado para não atingir vasos sanguíneos ou outras estruturas como as glândulas parótidas (Figura 4.5). 
Figura 4.5- Bloqueio anestésico do musculo masseter

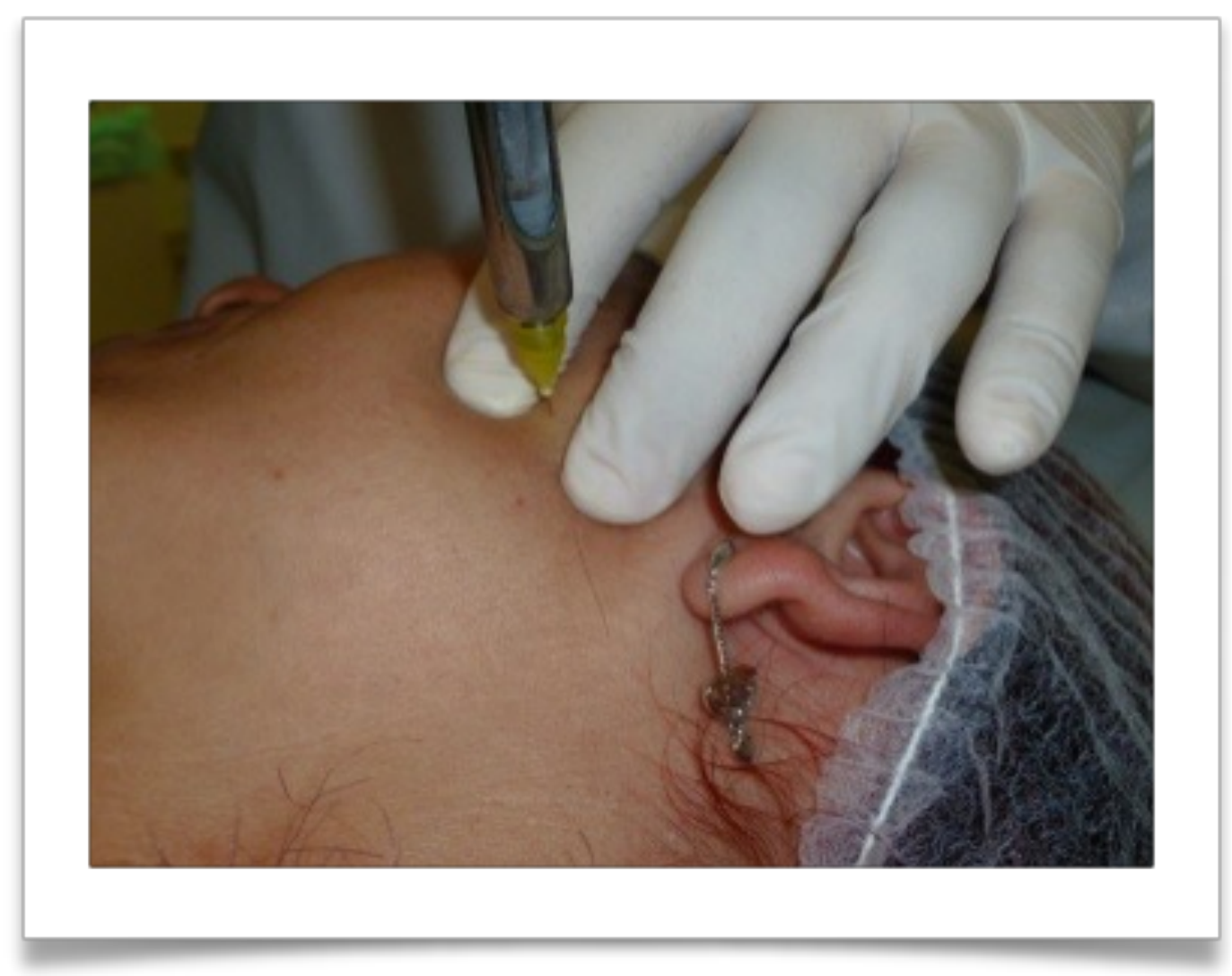

\subsection{REGISTRO DA DOR}

A dor relatada dos pacientes foi mensurada e registrada pela escala visual analógica na mesma medição de intervalo de tempo que a termografia, ou seja, a 2 minutos antes do bloqueio anestésico, dois minutos após o bloqueio anestésico e 10 minutos após o bloqueio anestésico. Imagens térmicas e avaliação do grupo controle de dor foram feitas no mesmo intervalo de tempo, ou seja, a mensuração inicial e dois intervalos de 2 minutos e 10 minutos depois do bloqueio anestésico. 


\subsection{ANÁLISE ESTATÍSTICA}

Depois de calibrados, os valores de temperatura em graus Celsius, correspondentes a área de $2 \mathrm{~mm}$, foram analisados estatisticamente para verificar se havia diferenças estatisticamente significantes na temperatura dos músculos com dor antes e após a aplicação de anestésico. Foram comparados ainda os dados referentes a temperatura do lado com dor anestesiado com o lado oposto, denominado controle.

Os dados obtidos através do RDC, relativos a dor muscular e os dados dos termogramas foram comparados para verificar se houve correlação entre alterações de temperatura e dor ao longo do tempo através de regressão linear. Todos os dados obtidos no RDC e de termografia foram submetidos a analise descritiva para avaliar que tipo de estatística seria o mais adequado e se eram normais. Dados que poderiam confundir os resultados foram analisados através de regressão linear para verificar se houve influência nos resultados verificados. 


\section{RESULTADOS}

Todos os pacientes deste estudo foram mulheres com: dor crônica, média de 33 meses desde que a dor se iniciou $(\sigma=103)$; idade média de 44 anos $(\sigma=12.55)$, média de índice de massa corpórea (IMC) de 25( $\sigma=3.69)$; intensidade característica da dor (ICD) médio de 70( $\sigma=19.48)$, média de pontos de incapacidade (DCA) de 0.69( $\sigma=0.55)$; média da pior dor sentida nos 6 últimos meses de 9; média da dor sentida nos últimos 6 meses $8(\sigma=0.95)$ e dor média relatada de $7.87(\sigma=1.45)$.

\subsection{TEMPERATURA MUSCULAR}

Os valores obtidos através da termografia representam a temperatura da pele sobre o músculo.

O valor médio da temperatura do lado com dor no tempo1(TPS2MB) foi de 32.47 $(\sigma=2.01)$, para o tempo2(TPS2MA) foi de 33.62 $(\sigma=2.14)$ e para o tempo 3(TPS10MA) foi de $33.28(\sigma=1.59)$.

O valor médio da temperatura no lado controle no tempo 1(TCS2MB) foi de 33.08 $(\sigma=1.70)$, no tempo 2 (TCS2MA) foi de $33.20(\sigma=1.44)$ e para o tempo 3(TCS10MA) foi de 33.28( $\sigma=1.59)$. (Figura 5.1) 
Figura 5.1- Variação da temperatura ao logo do tempo

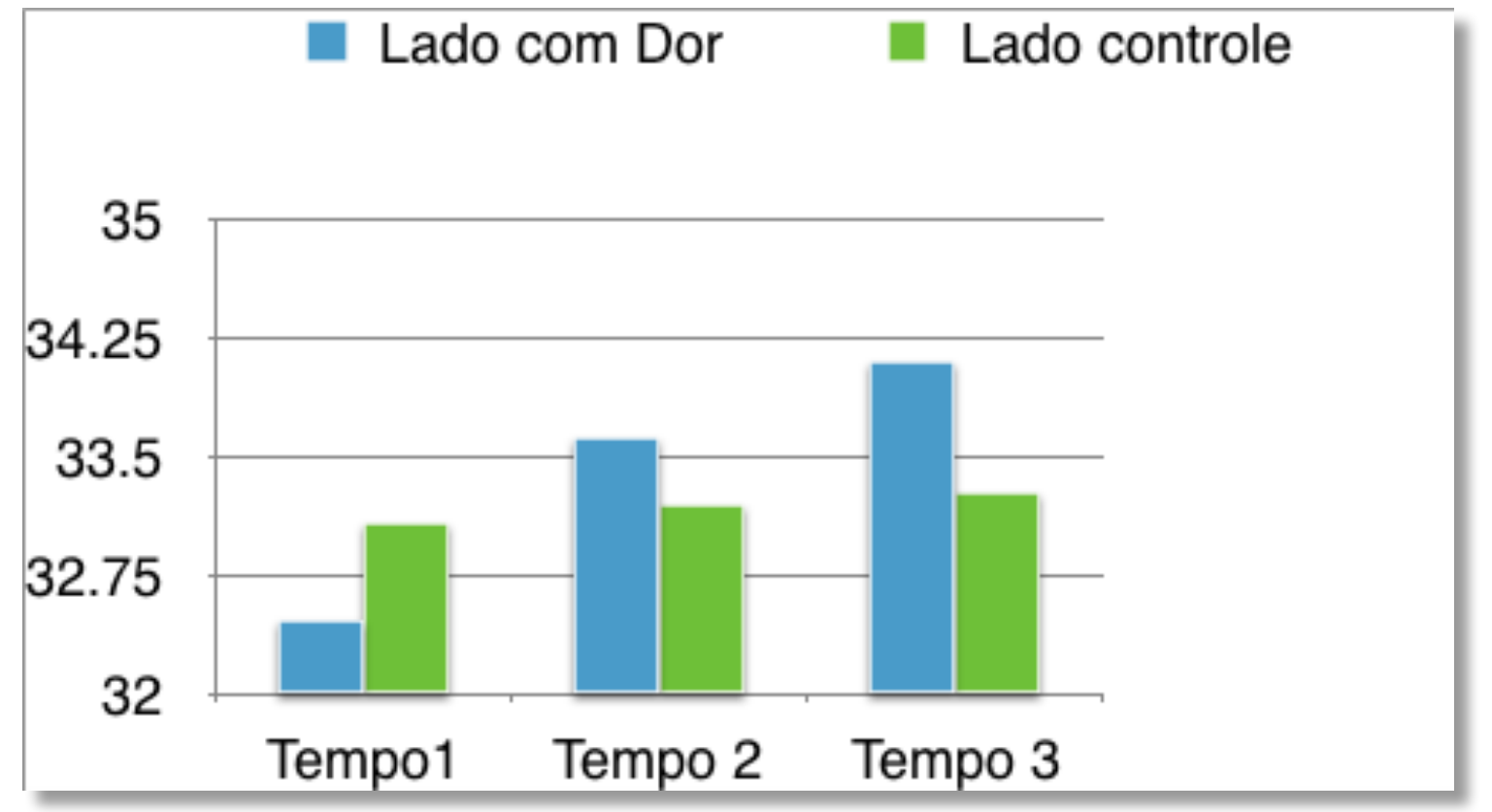

\subsection{DOR MUSCULAR}

O valor médio da dor medido na escala visual analógica (VAS) no tempo1 (P2MB) foi de $6.12(\sigma=2.23)$, no tempo $2(P 2 M A)$ foi de $1.64(\sigma=2.02)$ e no tempo $3(\mathrm{P} 10 \mathrm{MA})$ foi de $0.45(\sigma=0.87)$. (Figura 5.2) 
Figura 5.2 - Variação da dor ao logo do tempo

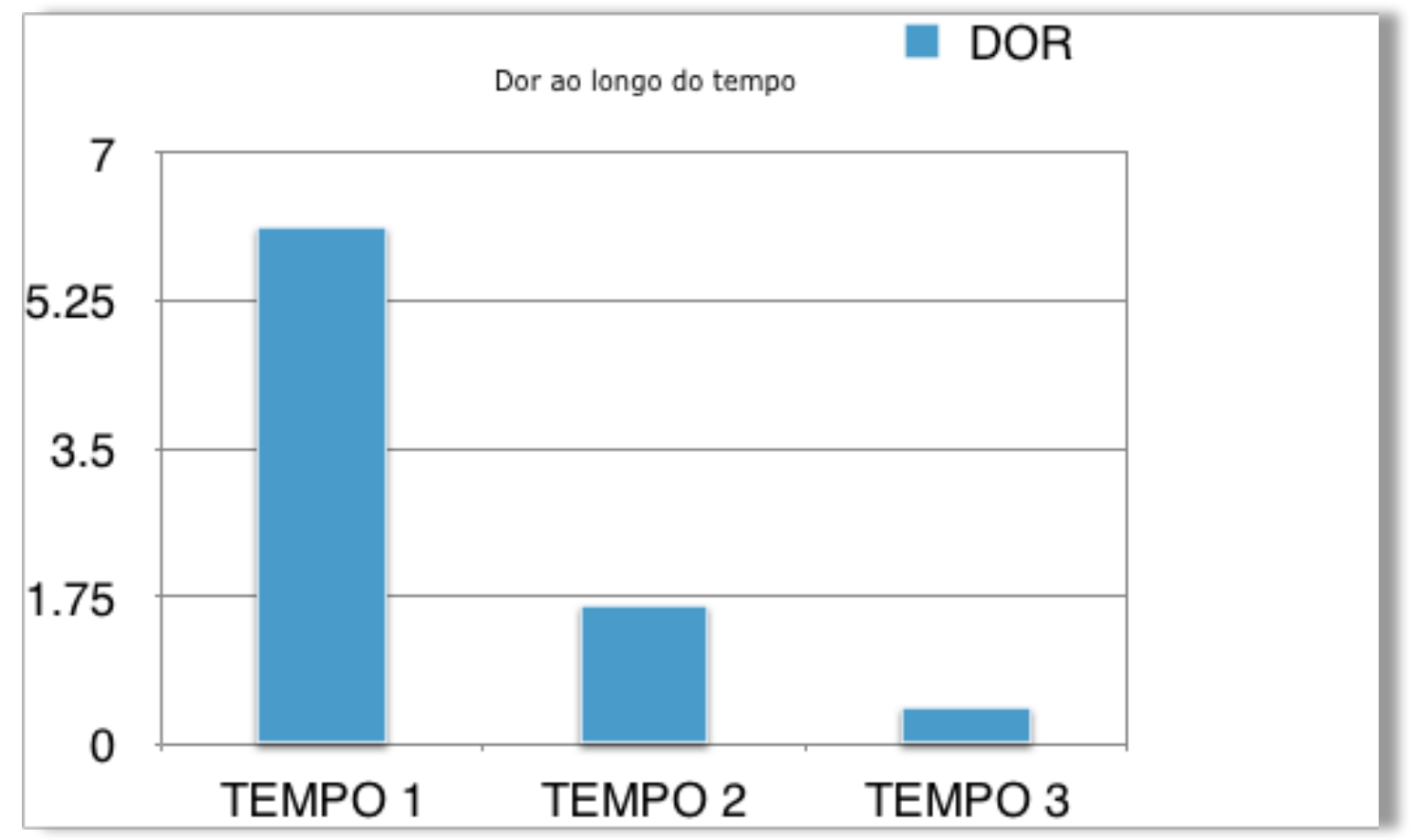

\subsection{ANÁLISE ESTATÍSTICA LONGITUDINAL DOS TEMPOS 1, 2 E 3 QUANTO A DOR RELATADA}

Para esta análise, os 3 intervalos, i.e., 2 minutos antes do bloqueio anestésico, 2 minutos após o bloqueio anestésico e 10 minutos após o bloqueio anestésico foram analisados quanto a dor relatada.

Comparando a dor relatada entre os tempos 1, 2 e 3, existiu uma diferença estatisticamente significante entre todos os intervalos. A média foi de 6.12 para o tempo 1, 1.64 para o tempo 2 e 0.45 para o tempo 3, com $\mathrm{P}<0.001$ entre tempo $1 \mathrm{e}$ tempo 2; $\mathrm{P}<0.002$ entre tempo 2 e tempo3 e $\mathrm{P}<0.001$ entre tempo 1 e tempo $3 \mathrm{com}$ limite de confiança de $95 \%$. 


\subsection{ANÁLISE ESTATÍSTICA LONGITUDINAL ENTRE OS TEMPOS 1, 2 E 3 QUANTO À TEMPERATURA NO LADO COM DOR}

Comparando a temperatura no lado com dor nos tempos 1 e 2, existiu uma diferença estatisticamente significante com $\mathrm{P}<0.001$ com limite de $95 \%$ de confiança.

Comparando a temperatura no lado com dor, existiu uma diferença estatisticamente significante entre os tempos 2 e 3 com $P<0.0048$ com limite de confiança de $95 \%$.

\subsection{ANÁLISE ESTATÍSTICA LONGITUDINAL ENTRE OS TEMPOS 1, 2 E 3 QUANTO À TEMPERATURA NO LADO CONTROLE}

Comparando a temperatura entre os tempos 1, 2 e 3 no lado controle, não houve diferença estatisticamente significante.

\subsection{ANÁLISE ESTATÍSTICA LONGITUDINAL ENTRE OS FATORES QUE PODERIAM INFLUENCIAR NA DIMINUICÃO DA DOR}

Dos possíveis fatores de confusão estudados, o único que apresentou associação estatística com a diminuição da dor foi o tempo com $\mathrm{P}<0.001$.

A variação na intensidade da dor ao longo dos tempos 1, 2 e 3 foi comparado ao IMC, idade, intensidade característica da dor (ICD), pontos de incapacidade (DCA) e tempo desde que a dor iniciou e nenhum destes fatores estava relacionado com a dor, com $p=0,89,0,68,0,81,0,95$ e 0,15 , respectivamente no limite de confiança de 95\%. (Tabela 5.1) 
Tabela 5.1- Associação de fatores e dor

\begin{tabular}{lcc}
\hline EFEITO & F value & Pr $>$ F \\
\hline Tempo & 105.41 & $<0.0001$ \\
IMC & 0.02 & 0.89 \\
IDADE & 0.17 & 0.68 \\
ICD & 0.06 & 0.81 \\
DCA & 0.00 & 0.95 \\
Tempo de dor & 2.11 & 0.15 \\
\hline
\end{tabular}

5.7 ANÁLISE ESTATÍSTICA LONGITUDINAL ENTRE OS FATORES QUE PODERIAM INFLUENCIAR A TEMPERATURA NO LADO COM DOR

Comparando fatores como o tempo, IMC, idade, ICD, DCA e tempo desde que a dor começou, só o tempo está relacionada com a mudança de temperatura, com $p$ $<0,0001$ (Tabela 5.2). 
Tabela 5.2 - Associação entre possíveis fatores de confusão e temperatura do lado com dor

\begin{tabular}{lcc} 
EFEITO & F value & Pr $>$ F \\
\hline Tempo & 29.46 & $<0.0001$ \\
IMC & 0.12 & 0.72 \\
IDADE & 3.79 & 0.06 \\
ICD & 1.08 & 0.30 \\
DCA & 0.03 & 0.85 \\
Tempo de dor & 5.31 & 0.029 \\
\hline
\end{tabular}

Os valores de temperatura no lado com dor e controle foram pareados e um TTest foi feito para verificar diferenças estatísticas.

Comparando diferença entre a temperatura inicial no tempo 1 e tempo 3 (após 12 minutos) no lado com bloqueio anestésico (TPS2MB - TPS10MA), houve uma diferença significativa com a média de - 1,74 e $\mathrm{P}<0,001$.

Comparando temperatura no lado com anestesia 2 minutos antes e 2 minutos após o bloqueio anestésico (TPS2MB - TPS2MA), houve uma diferença estatística com um valor médio de $-1,25$ e $P<0,001$.

Comparando temperatura no lado com dor no tempo 2 e tempo 3(TPS2MA TPS10MA), houve uma diferença estatística com um valor médio de - 0,48 e $P<0,010$.

Comparando temperatura entre os lados com e sem a temperatura no tempo 1 (TPS2MB - TCS2MB), houve uma diferença estatística com uma média de 0,79 e P $<0,001$ com $95 \%$ de limites de confiança. 
Comparando temperatura nos lados com e sem anestesia 2 minutos após o bloqueio anestésico (TPS2MA - TCS2MA), não houve diferença estatística com uma média de $-0,53$ e $\mathrm{P}<0,054$ com $95 \%$ de limites de confiança.

Comparando temperatura entre os lados com e sem anestesia, 10 minutos após o bloqueio anestésico (TPS10MA - TCS10MA), houve diferença estatística com uma média de $-0,77$ e $\mathrm{P}<0,001$ com $95 \%$ de limite de confiança.

Comparando a dor inicial e 2 minutos após bloqueio anestésico (P2MB - P2MA) houve uma diferença significativa com uma média de 4,32, desvio padrão 2,38 e $\mathrm{P}$ $<0,001$ com $95 \%$ dos limites de confiança.

Comparando a dor inicial com a dor 10 minutos após bloqueio anestésico (P2MB - P10MA) houve uma diferença significativa com uma média de 5.67, Desvio padrão de 2.23 e $P<0,001$ com $95 \%$ dos limites de confiança. 


\section{DISCUSSÃO}

Após bloqueio anestésico do músculo masseter, 27 de 31 pacientes tiveram dor reduzida a zero, confirmando o diagnóstico inicial usado para selecionar os voluntários. Isto também significa que a injeção de anestésico é um método confiável para alívio imediato da dor muscular.

A temperatura aumentou no lado da dor após bloqueio anestésico em 29 dos 31 pacientes, conforme o gráfico (Figura 6.1). A dor diminuiu em todos os pacientes (Figura 6.2). No estudo longitudinal entre os intervalos antes do bloqueio anestésico, 2 minutos após o bloqueio anestésico e 10 minutos após, só o tempo foi um efeito relacionado estatisticamente à diminuição da dor. O valor médio para redução total na dor após 10 minutos foi de 5,67 em unidades de dor e o valor médio para o aumento de temperatura no mesmo intervalo foi de 1,74 unidades em graus Celsius.

Figura 6.1- Teste pareado para variação da temperatura

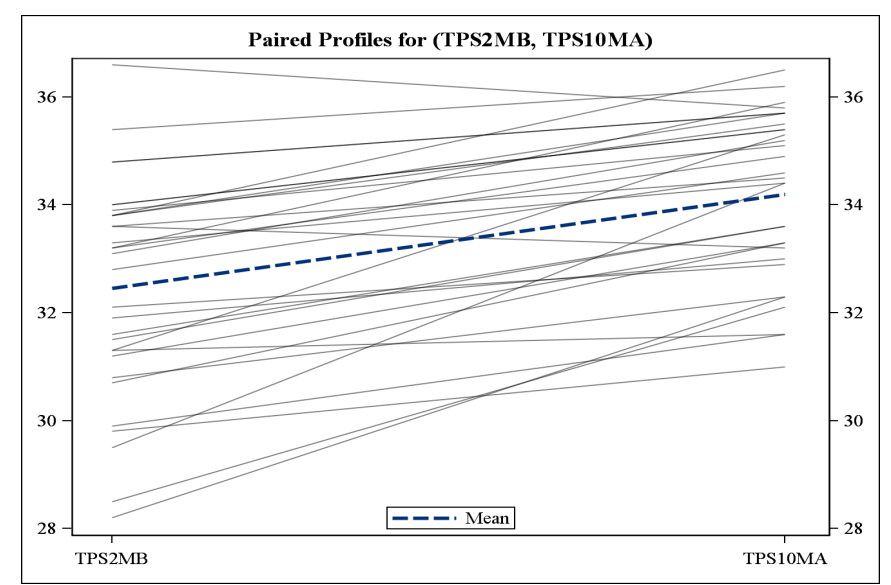

Cada linha horizontal do gráfico representa a variação de temperatura de cada um dos 31 pacientes estudados no intervalo entre dois minutos antes do bloqueio anestésico no lado com dor (TPS2MB) e 10 minutos após o bloqueio anestésico (TPS10MA). A linha azul (linha pontilhada azul) representa a media de temperatura dos 31 pacientes antes e depois do bloqueio anestésico e mostra que houve aumento da temperatura (Figura 6.1). 
Figura 6.2- Teste pareado para dor

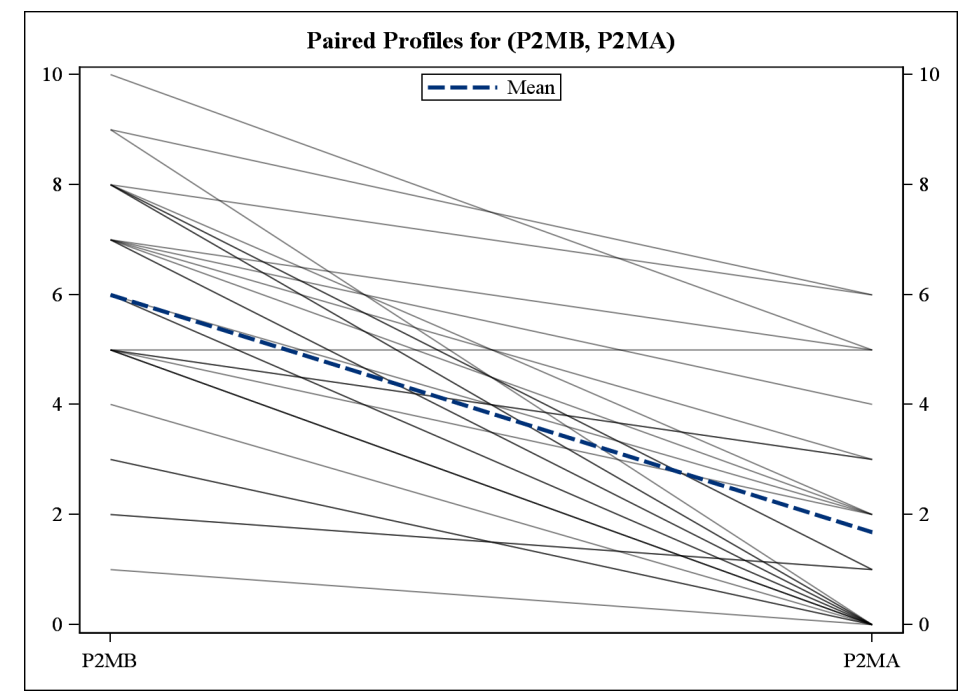

No gráfico acima, as linhas horizontais representam a variação da dor em cada um dos 31 pacientes estudados no intervalo de tempo entre 2 minutos antes do bloqueio anestésico e 2 minutos após o bloqueio anestésico. A linha pontilhada azul representa a média dos 31 pacientes e mostra uma diminuição da dor (Figura 6.2).

Dos 31 pacientes estudados, 27 apresentaram dor 0 dez minutos após anestesia e este valor foi difícil de se relacionar diretamente com a variação da temperatura porque a escala de temperatura é diferente da escala de dor, ou seja, 2 magnitudes diferentes. O valor de alteração da grandeza dor não é proporcional ao valor de alteração da grandeza temperatura.

Sobre os possíveis fatores de confusão, só o tempo desde que a dor iniciou pareceu estar relacionada à variação na dor. Isto pode ser explicado pela presença de dor crônica em todos os pacientes do presente estudo. Isso mostra a importância do acompanhamento de pacientes com DTM e da importância do questionário RDC para o correto diagnóstico.

O valor médio de temperatura foi menor para o lado com dor em comparação com o lado controle antes do bloqueio anestésico. Os termogramas obtidos mostraram diferenças estatísticas entre os dois lados estudados antes do bloqueio anestésico. 
Enquanto alguns investigadores observaram temperatura maior do lado com dor em relação ao lado oposto (Berry; Yemm, 1971; Sundqvist; Fischer, 1986; Kawano et al., 1993), encontramos o lado com dor hiporradiante em relação ao lado controle. Todos os pacientes da nossa investigação apresentavam dor crônica, com tempo médio de 33 meses desde que a dor havia iniciado. Por isso, esperávamos uma temperatura mais baixa do musculo com dor pela diminuição do fluxo sanguíneo, devido à diminuição da atividade muscular causada pela dor de longa duração.

Zhang et al. (2009) investigaram o efeito do estímulo doloroso de pontos gatilho latentes miofasciais (PGM) e termografia na medição do fluxo sanguíneo da pele. O estímulo doloroso foi obtido por uma injeção de glutamato $(0,1 \mathrm{ml}, 0,5 \mathrm{M}) \mathrm{em}$ um PGM latente localizado nos músculos braquiorradiais. Uma injeção de glutamato em um ponto não-PGM serviu como controle. A intensidade da dor (escala visual analógica [VAS]) foi avaliada após a injeção de glutamato. O limiar de dor à pressão (PPT) foi registrado bilateralmente no músculo braquiorradial antes e depois da dor induzida por glutamato. O fluxo sanguíneo da pele e a temperatura da superfície da pele foram medidos bilateralmente com termografia nos antebraços antes, durante e depois da dor induzida por glutamato. O estudo demonstrou uma resposta do fluxo sanguíneo da pele atenuada após a estimulação dolorosa dos PGM latentes em comparação com os não-PGM, sugerindo aumento da atividade de vasoconstrição simpática em PGM latentes. Assim, em nosso estudo, esperávamos um aumento na temperatura da pele sobre o músculo masseter após bloqueio anestésico por causa do relaxamento muscular e aumento do fluxo sanguíneo e obtivemos esta resposta com diferenças estatísticas de temperatura entre os tempos 1, 2 e 3 no lado com dor, enquanto o lado controle não teve mudanças de temperatura estatisticamente significantes nos mesmos intervalos de tempo.

Hong e Hsueh (1996) compararam pacientes com a síndrome dolorosa miofascial (MPS), causada por PG ativos e síndrome da fibromialgia (FMS) e pacientes com MPS devido a PG e avaliaram que a injeção de anestésico no ponto gatilho foi um procedimento valioso para o alívio da dor para pacientes em ambos os grupos. Apesar de termos observado a dor por um período de apenas 12 minutos, encontramos uma diminuição significativa da dor em todos os pacientes avaliados, mostrando que este tipo de tratamento para a dor miofascial é eficaz. 
Figura 6.3- Teste pareado de temperatura dos 31 indivíduos antes da anestesia

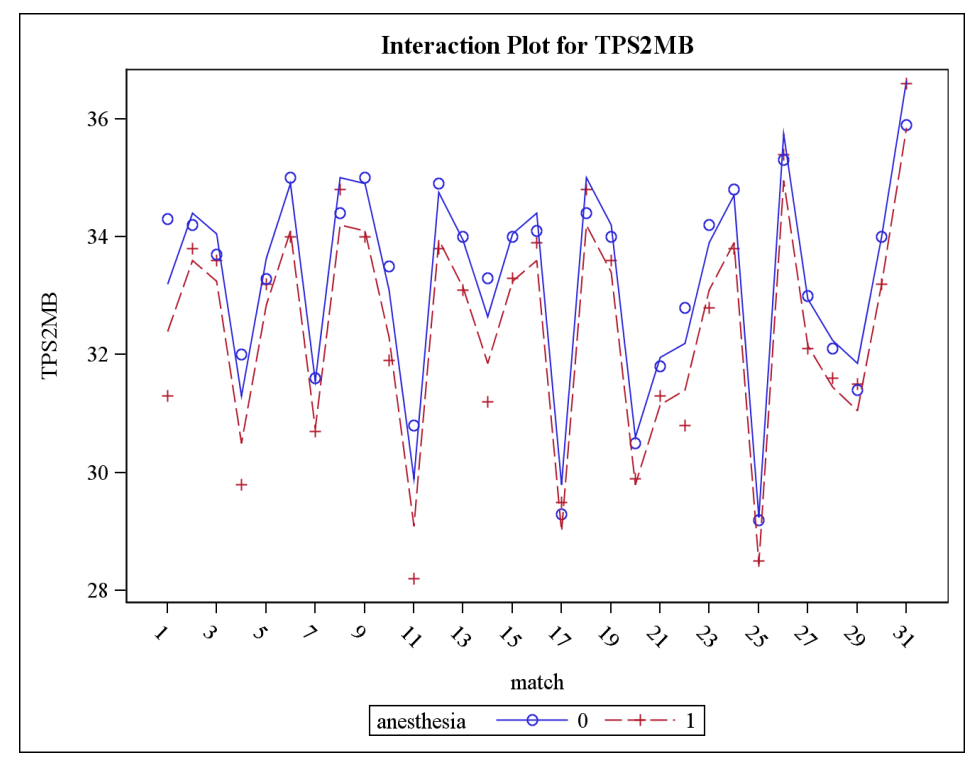

A temperatura do lado com dor dois minutos antes de receber anestesia estava mais baixa que a temperatura no lado controle e que não recebeu anestesia. Isto pode ser facilmente observado no gráfico da Figura $6.3 \mathrm{com}$ a linha azul, que representa a temperatura pareada de cada um dos pacientes no lado com dor antes de receber anestesia e a linha pontilhada vermelha mostrando o lado controle dos 31 pacientes estudados ao mesmo tempo.

No tempo 2, i.e., e minutos após o bloqueio anestésico já podemos observar uma inversão das linhas azul e vermelha, onde o lado com dor e que recebeu anestesia apresenta temperatura mais alta que o lado controle (Figura 6.4). 
Figura 6.4- Teste pareado de temperatura dos 31 indivíduos depois da anestesia

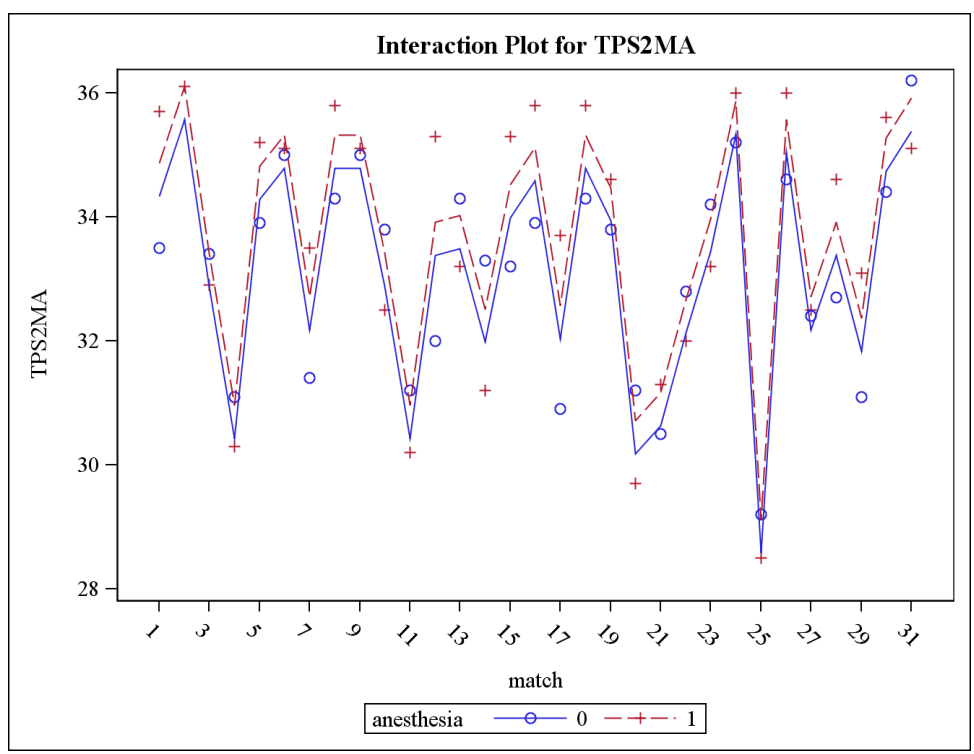

Pode-se observar que nos 3 gráficos em sequência que representam a temperatura pareada do lado com dor e sem dor, inicialmente a linha azul que representa o lado controle e que não recebeu anestesia apresenta-se mais alta do que a linha pontilhada vermelha que representa o lado com dor (Figura 6.3). Depois que a anestesia foi aplicada, as linhas se invertem mostrando que o lado que recebeu anestesia passou a apresentar temperatura mais alta que o lado controle (Figura 6.4). Apesar disto, não houve diferença estatisticamente significante entre o lado que recebeu anestesia e o lado controle neste intervalo de tempo. Depois de 10 minutos da aplicação do anestésico a inversão das linhas se mantem e a diferença de temperatura aumenta e a diferença estatística volta a aparecer, porém, com temperatura mais alta do lado que recebeu anestesia em comparação com o lado controle (Figura 6.5).

No intervalo de tempo 3, o gráfico abaixo mostra uma linha azul que representa a temperatura do lado controle dez minutos depois de receber anestesia e a linha pontilhada vermelha mostra o lado que recebeu anestesia dos 31 pacientes estudados ao mesmo tempo. 
Figura 6.5 - Teste pareado de temperatura dos 31 indivíduos ao minutos depois da anestesia

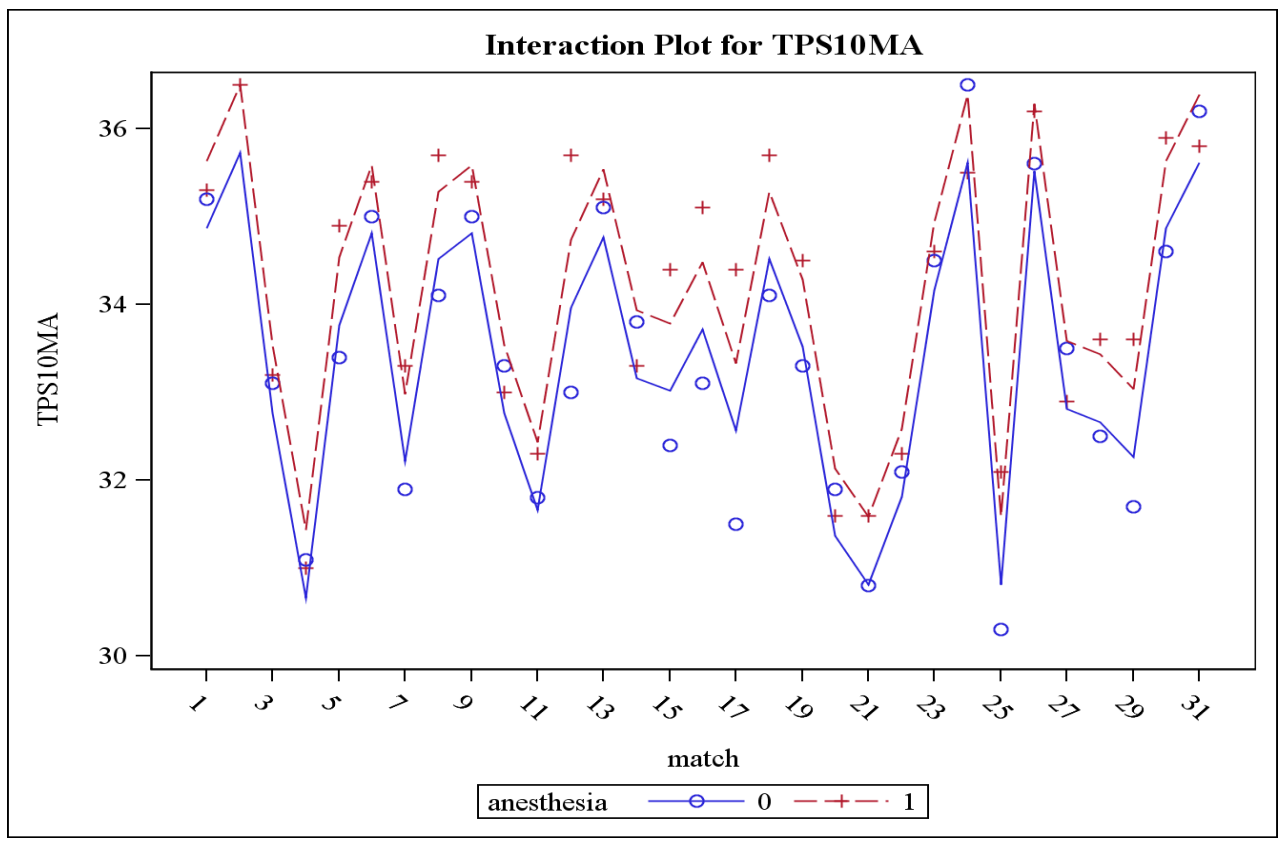




\section{CONCLUSÃO}

Pela análise dos resultados estatísticos podemos concluir que:

- Existe uma associação negativa entre a dor muscular e a temperatura muscular. 


\section{REFERÊNCIAS}

Bartuzi P, Roman-Liu D, Wisniewski T. The influence of fatigue on muscle temperature. Int J Occup Saf Ergon. 2012;18(2):233-43.

Berry DC, Yemm R. Variations in skin temperature of the face in normal subjects and in patients with mandibular dysfunction. Br J Oral Surg. 1971;8(3):242-7.

Biagioni PA, Longmore RB, McGimpsey JG, Lamey PJ. Infrared thermography. Its role in dental research with particular reference to craniomandibular disorders. Dentomaxillofac Radiol. 1996;25(3):119-24.

Dibai Filho AV, Packer AC, Costa AC, Berni-Schwarzenbeck KC, Rodrigues-Bigaton $D$. Assessment of the upper trapezius muscle temperature in women with and without neck pain. J Manip Physiol Ther. 2012;35(5):413-7.

Ford RG, Ford KT. Thermography in the diagnosis of headache. Semin Neurol. 1997;17(4):343-9.

Frost FA, Jessen B, Siggaard-Andersen J. A control, double-blind comparison of mepivacaine injection versus saline injection for myofascial pain. Lancet. 1980;1(8167):499-500.

Haddad DS, Brioschi ML, Vardasca R, Weber M, Crosato EM, Arita ES.

Thermographic characterization of masticatory muscle regions in volunteers with and without myogenous temporomandibular disorder: preliminary results. Dentomaxillofac Radiol. 2014:20130440.

Hong CZ, Hsueh TC. Difference in pain relief after trigger point injections in myofascial pain patients with and without fibromyalgia. Arch Phys Med Rehabil. 1996;77(11):1161-6.

Kawano W, Kawazoe T, Tanaka M, Hikida Y. Deep thermometry of temporomandibular joint and masticatory muscle regions. J Prosthet Dent. 1993;69(2):216-21.

Morimoto T, Takada K, Hijiya H, Yasuda Y, Sakuda M. Changes in facial skin temperature associated with chewing efforts in man: a thermographic evaluation. Arch Oral Biol. 1991;36(9):665-70.

\footnotetext{
${ }^{1}$ De acordo com estilo Vancouver.
} 
Ohrbach R, Turner JA, Sherman JJ, Mancl LA, Truelove EL, Schiffman EL, et al. The Research Diagnostic Criteria for Temporomandibular Disorders. IV: evaluation of psychometric properties of the Axis II measures. J Orofac Pain. 2010;24(1):48-62.

Pogrel MA, McNeill C, Kim JM. The assessment of trapezius muscle symptoms of patients with temporomandibular disorders by the use of liquid crystal thermography. Oral Surg Oral Med Oral Pathol Oral Radiol Endod. 1996;82(2):145-51.

Schiffman EL, Ohrbach R, Truelove EL, Tai F, Anderson GC, Pan W, et al. The research diagnostic criteria for temporomandibular disorders. $\mathrm{V}$ : methods used to establish and validate revised Axis I diagnostic algorithms. J Orofac Pain.

2010a;24(1):63-78.

Schiffman EL, Truelove EL, Ohrbach R, Anderson GC, John MT, List T, et al. The research diagnostic criteria for temporomandibular disorders. I: overview and methodology for assessment of validity. J Orofac Pain. 2010b;24(1):7-24.

Sundqvist B, Fischer JE. Pressure-temperature phase boundaries in KC24: Evidence for a kinetically-hindered low-temperature staging transition. Phys Rev B Condens Matter. 1986;34(5):3532-5.

Truelove E, Pan W, Look JO, Mancl LA, Ohrbach RK, Velly AM, et al. The Research Diagnostic Criteria for Temporomandibular Disorders. III: validity of Axis I diagnoses. J Orofac Pain. 2010;24(1):35-47.

Venancio Rde A, Alencar FG, Jr., Zamperini C. Botulinum toxin, lidocaine, and dryneedling injections in patients with myofascial pain and headaches. Cranio.

2009;27(1):46-53.

Zhang Y, Ge HY, Yue SW, Kimura Y, Arendt-Nielsen L. Attenuated skin blood flow response to nociceptive stimulation of latent myofascial trigger points. Arch Phys Med Rehabil. 2009;90(2):325-32. 


\section{APÊNDICE A - Termo de Consentimento Livre e Esclarecido (TCLE)}

Termo de Consentimento Livre e Esclarecido (TCLE)

$\mathrm{Eu}$, , Rg:

$\mathrm{CPF}$ abaixo assinado, estou devidamente esclarecida sobre todas as condições do Projeto de pesquisa intitulado: "Estudo da Correlação Entre Termografia e Controle da Dor Muscular com Bloqueio Anestésico", tendo como pesquisador responsável Marcelo Weber.

As informações abaixo são para esclarecer e pedir a sua participação voluntária neste estudo que tem por finalidade avaliar se a temperatura do músculo com dor aumenta após o bloqueio anestésico. Para isso será aplicado um questionário inicial e preenchimento de uma ficha. Em seguida, será realizado um exame de imagem denominado termografia, aplicação do anestésico intramuscular e novo exame termográfico. O bloqueio anestésico serve como tratamento da dor muscular e também auxilia o diagnóstico de sua dor. Através da assimetria da temperatura do músculo que estamos estudando poderemos saber se existe uma alteração metabólica no seu músculo.

A sua participação nesta pesquisa ajudará a entendermos melhor a alteração metabólica que ocorre no músculo masséter, quando os pacientes apresentam dor.

Sua participação é voluntária e você não receberá ajuda de custo direto.

O pesquisador responsável prestará esclarecimentos a eventuais dúvidas que podem surgir a qualquer momento, durante o andamento da pesquisa, onde poderá ser encontrado pelo telefone (41)9984-4044. Qualquer dúvida quanto às questões éticas , o CEP poderá ser consultado no endereço rua Professor Lineu Prestes, 2227 São Paulo-SP.

Declaro que tenho pleno conhecimento dos direitos e das condições que me foram asseguradas, a seguir relacionadas:

1- Liberdade de retirar o meu consentimento e de deixar de participar do estudo, a qualquer momento, sem que isso traga prejuízo à continuidade do meu tratamento.

2- A segurança de que não serei identificado e que será mantido o caráter confidencial da informação relacionada a minha privacidade.

3- O compromisso que me será prestada informação atualizada durante o estudo, ainda que esta possa afetar minha vontade de continuar participando dele.

4- O compromisso de que serei devidamente acompanhada e assistida durante todo o período de minha participação no projeto, bem como de que será garantida a continuidade do meu tratamento na clínica em que fui selecionada, após a conclusão dos trabalhos de pesquisa.

Declaro, ainda, que concordo inteiramente com as condições que me foram apresentadas e que, voluntariamente, manifesto a minha vontade em participar do referido projeto.

São Paulo, de de

Pesquisador

Nome da voluntária:

Telefones para contato:
Endereço: e-mail 
APÊNDICE B - Ficha de Termografia

\section{EXAME TERMOGRÁFICO}

NOME:

Peso:

Altura:

Data: I I .

Temperatura ambiente:

Umidade relativa

Medicamentos que faz uso:

Você tem alergia a medicamentos ou anestésico local?

Esteve com alergias ou problemas de pele ou espinhas ou sofreu algum trauma na região da cabeça nos últimos 15 dias?

$\square \operatorname{Sim}$.

Que parte do corpo?

Você tem cetoacidose diabética, hipoglicemia, hipotireoidismo, hipertensão, doenças respiratórias, artrite reumatóide, fibromialgia, enxaqueca ou está grávida?

\begin{tabular}{|l|l|l|l|}
\hline Local & $\begin{array}{l}\text { Temperatura } \\
2 \text { min antes }\end{array}$ & $\begin{array}{l}\text { Temperatura } \\
2 \text { min após }\end{array}$ & $\begin{array}{l}\text { Temperatura } \\
\text { 10min depois }\end{array}$ \\
\hline Músculo masseter (R) & & & \\
\hline Músculo masseter (L) & & & \\
\hline Escala de dor VAS & & & \\
\hline
\end{tabular}

\begin{tabular}{|l|l|l|l|}
\hline Local & Temperatura 2 min antes & Temperatura 2min besuntados & Temperatura 10 min besuntados \\
\hline Músculo temporal $(\mathrm{R})$ & & & \\
\hline Músculo temporal $(\mathrm{L})$ & & & \\
\hline Músculo trapézio $(\mathrm{R})$ & & & \\
\hline Músculo trapézio $(\mathrm{L})$ & & & \\
\hline ECM $(\mathrm{R})$ & & & \\
\hline $\mathrm{ECM}(\mathrm{L})$ & & & \\
\hline
\end{tabular}


ANEXO A - Termo de aprovação do Comitê de Ética

FACULDADE DE
ODONTOLOGIA DA
UNIVERSIDADE DE SÃO

DADOS DO PROJETO DE PESQUISA

Título da Pesquisa: Estudo da Correlação Entre Termografia e Controle da Dor Muscular com Bloqueio Anestésico

Pesquisador: Marcelo Weber

Área Temática:

Versão: 2

CAAE: 31012714.3 .0000 .0075

Instituição Proponente: FUNDACAO PARA O DESENVOLVIMENTO CIENT E TEC ODONTOLOGIA

Patrocinador Principal: Financiamento Próprio

\section{DADOS DO PARECER}

Número do Parecer: 754.595

Data da Relatoria: $18 / 08 / 2014$

Apresentação do Projeto:

A dor muscular tem diversas formas de abordagem quanto ao diagnóstico e terapias, este projeto intitulado "Estudo da Correlação Entre Termografia e Controle da Dor Muscular com Bloqueio Anestésico" que será executado na Clínica da Fundação para o Desenvolvimento Científico e Tecnológico da Odontologia(FUNDECTO), utilizará a termografia para avaliar a redução da dor no músculo masseter pós a aplicação de anestésico neste músculo.

Objetivo da Pesquisa:

O objetivo da pesquisa será avaliar a correlação de dados termográficos com a redução da dor de pacientes tratados com bloqueio anestésico e agulhamento.

Avaliação dos Riscos e Benefícios:

O risco relatado pelos pesquisadores é a injeção de anestésico intramuscular, com possivel alergia ao princípio ativo, ou seja,a mepivacaína e está muito bem relatado no projeto. Como benefício o projeto procura um protocolo para diagnóstico de dor muscular local, através do termógrafo e como benefício direto os pacientes, que tiverem seu diagnóstico confirmado pela termografia, o tratamento para a dor muscular.

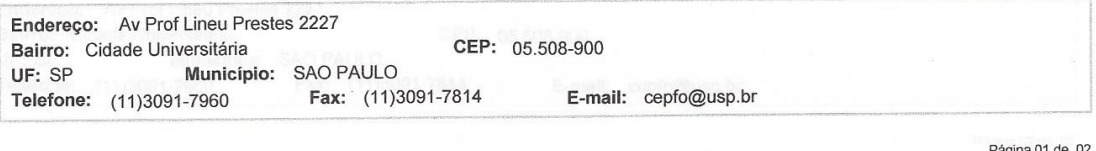




\section{FACULDADE DE \\ ODONTOLOGIA DA UNIVERSIDADE DE SÃO}

Continuação do Parecer: 754.595

Comentários e Considerações sobre a Pesquisa:

A pesquisa está bem delineada e pode trazer importantes contribuição para a relação terapia/diagnostico da dor muscular.

Considerações sobre os Termos de apresentação obrigatória:

Foram apresentados os termos de apresentação obrigatória: folha de rosto, projeto da integra, TCLE e autorização para a execução da pesquisa na FUNDECTO. Todos os documentos em conformidade as exigências do CEPFO.

Recomendações:

Não há recomendações, apenas lembar aos pesquisadores que tendo em vista a legislação vigente, devem ser encaminhados ao CEP-FOUSP relatórios parciais anuais referentes ao andamento da pesquisa e relatório final ao término do trabalho. Qualquer modificação do projeto original deve ser apresentada a este CEP, de forma objetiva e com justificativas, para nova apreciação.

Conclusões ou Pendências e Lista de Inadequações:

No projeto não inadequações ou nada que fira a ética em pesquisa.

Situação do Parecer:

Aprovado

Necessita Apreciação da CONEP:

Não

Considerações Finais a critério do CEP:

SAO PAULO, 18 de Agosto de 2014

Assinado por:

Maria Gabriela Haye Biazevic

(Coordenador)

Endereço: Av Prof Lineu Prestes 2227

UF: SP Municipio: SAO PAULO

CEP: $05.508-900$

Telefone: (11)3091-7960 _ Fax: (11)3091-7814

E-mail: cepfo@usp.br 
ANEXO B - RDC/TMD PORTUGUESE

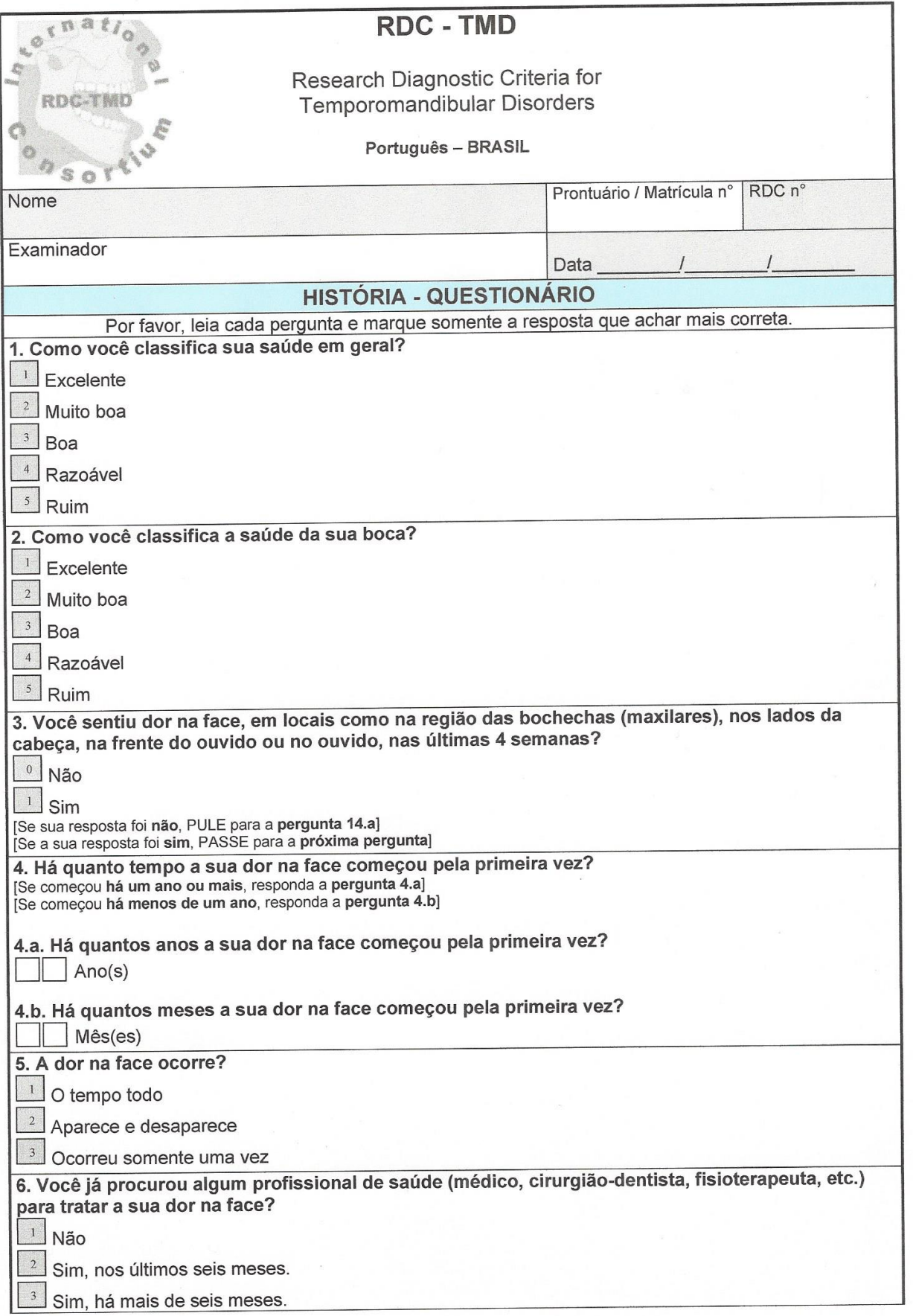




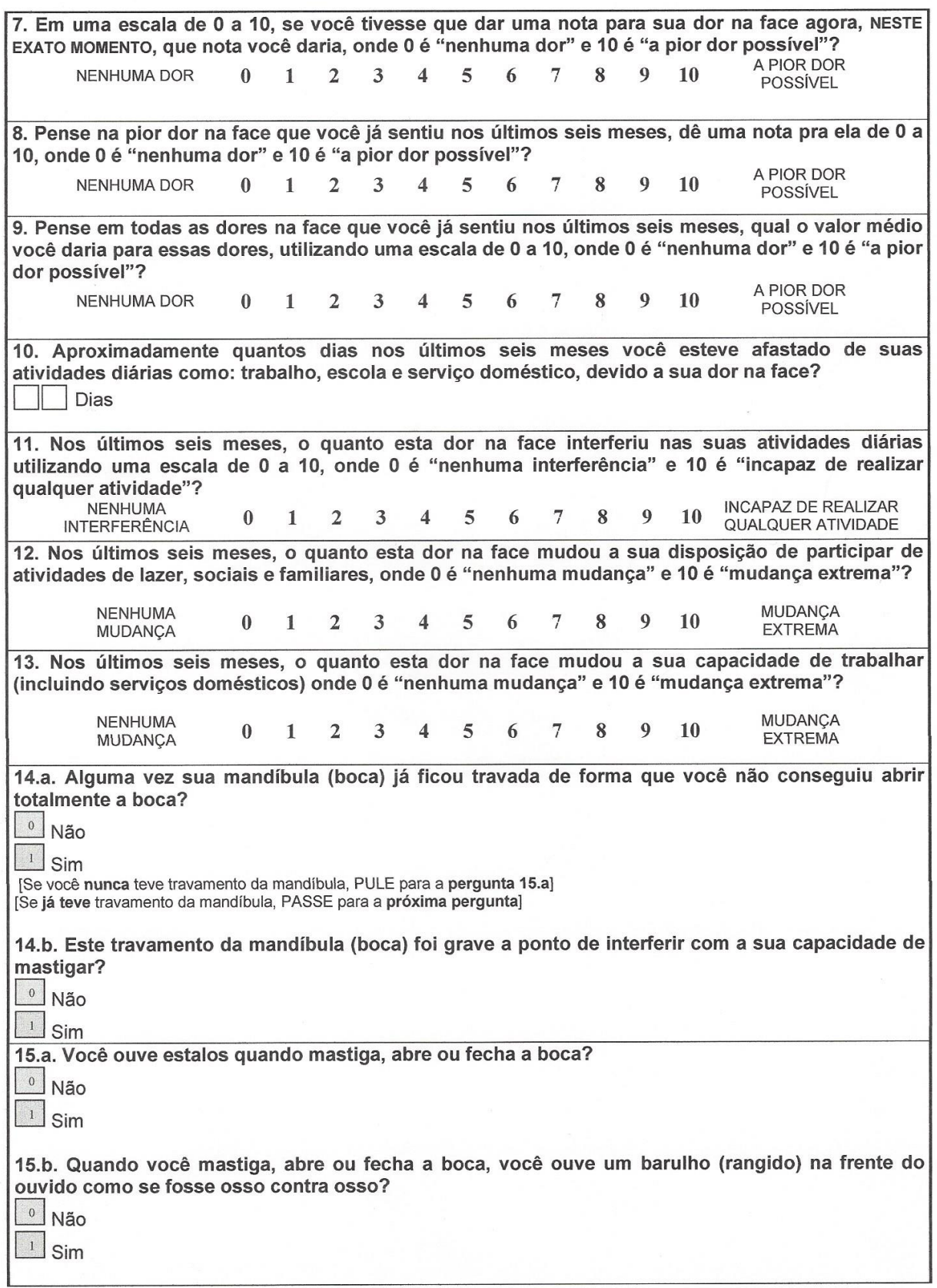


15.c. Você já percebeu ou alguém falou que você range (ringi) ou aperta os seus dentes quando está dormindo?

0 Não

1 Sim

15.d. Durante o dia, você range (ringi) ou aperta os seus dentes?

0 Não

1 Sim

15.e. Você sente a sua mandíbula (boca) "cansada" ou dolorida quando você acorda pela manhã?

0 Não

1 Sim

15.f. Você ouve apitos ou zumbidos nos seus ouvidos?

0 Não

1 Sim

15.g. Você sente que a forma como os seus dentes se encostam é desconfortável ou diferente/ estranha?

0 Não

1 Sim

16.a. Você tem artrite reumatóide, lúpus, ou qualquer outra doença que afeta muitas articulações (juntas) do seu corpo?

0 Não

1 Sim

16.b. Você sabe se alguém na sua família, isto é seus avós, pais, irmãos, etc. já teve artrite reumatóide, lúpus, ou qualquer outra doença que afeta várias articulações (juntas) do corpo?

0 Näo

1 Sim

16.c. Você já teve ou tem alguma articulação (junta) que fica dolorida ou incha sem ser a articulação (junta) perto do ouvido (ATM)?

0 Não

1 Sim

[Se você não teve dor ou inchaço, PULE para a pergunta 17.a.]

[Se você já teve, dor ou inchaço, PASSE para a próxima pergunta]

16.d. A dor ou inchaço que você sente nessa articulação (junta) apareceu várias vezes nos últimos 12 meses ( 1 ano)?

0 Não

1 Sim

17.a. Você teve recentemente alguma pancada ou trauma na face ou na mandíbula (queixo)?

0 Não

1 Sim

[Se sua resposta foi não, PULE para a pergunta 18]

[Se sua resposta foi sim, PASSE para a próxima pergunta]

17.b. A sua dor na face (em locais como a região das bochechas (maxilares), nos lados da cabeça, na frente do ouvido ou no ouvido) já existia antes da pancada ou trauma?

0 Não

1 Sim

18. Durante os últimos seis meses você tem tido problemas de dor de cabeça ou enxaquecas? 0 Não

1 Sim 


\begin{tabular}{|c|c|c|c|c|c|}
\hline \multirow{2}{*}{\multicolumn{3}{|c|}{$\begin{array}{l}\text { 19. Quais atividades a sua dor na face ou problema na mandíbula (qu } \\
\text { prejudicam? }\end{array}$}} & )), & & \\
\hline & & & \multicolumn{2}{|l|}{ SIM } & \\
\hline \multicolumn{2}{|l|}{ a. Mastigar } & 0 & \multicolumn{2}{|l|}{1} & \\
\hline \multicolumn{2}{|l|}{ b. Beber (tomar líquidos) } & 0 & \multicolumn{2}{|l|}{$\frac{1}{1}$} & \\
\hline \multicolumn{2}{|l|}{ c. Fazer exercícios físicos ou ginástica } & 0 & \multicolumn{2}{|l|}{1} & \\
\hline \multicolumn{2}{|l|}{ d. Comer alimentos duros } & 0 & \multicolumn{2}{|l|}{1} & \\
\hline \multicolumn{2}{|l|}{ e. Comer alimentos moles } & 0 & \multicolumn{2}{|l|}{1} & \\
\hline \multicolumn{2}{|l|}{ f. Sorrir/gargalhar } & 0 & \multicolumn{2}{|l|}{$\frac{1}{1}$} & \\
\hline \multicolumn{2}{|l|}{ g. Atividade sexual } & 0 & 1 & & \\
\hline h. Limpar os dentes ou a face & & 0 & 1 & & \\
\hline i. Bocejar & & 0 & 1 & & \\
\hline j. Engolir & & 0 & 1 & & \\
\hline k. Conversar & & 0 & 1 & & \\
\hline I. Ficar com o rosto normal: sem a aparência de dor ou triste & & 0 & 1 & & \\
\hline 20. Nas últimas quatro semanas, o quanto você tem estadc & gu & ou & eocup & & \\
\hline & $\begin{array}{l}\text { Nemum } \\
\text { pouroo }\end{array}$ & Umpouso & Moderadamentie & Muilo & Extrenamente \\
\hline a. Por sentir dores de cabeça & 0 & 1 & 2 & 3 & 4 \\
\hline b. Pela perda de interesse ou prazer sexual & 0 & 1 & 2 & 3 & 4 \\
\hline c. Por ter fraqueza ou tontura & 0 & 1 & 2 & 3 & 4 \\
\hline d. Por sentir dor ou "aperto" no peito ou coração & 0 & 1 & 2 & 3 & 4 \\
\hline e. Pela sensação de falta de energia ou lentidão & 0 & 1 & 2 & 3 & 4 \\
\hline f. Por ter pensamentos sobre morte ou relacionados ao ato de morrer & 0 & 1 & 2 & 3 & 4 \\
\hline g. Por ter falta de apetite & 0 & 1 & 2 & 3 & 4 \\
\hline h. Por chorar facilmente & 0 & 1 & 2 & 3 & 4 \\
\hline i. Por se culpar pelas coisas que acontecem ao seu redor & 0 & 1 & 2 & 3 & 4 \\
\hline j. Por sentir dores na parte inferior das costas & 0 & 1 & 2 & 3 & 4 \\
\hline k. Por se sentir só & 0 & 1 & 2 & 3 & 4 \\
\hline I. Por se sentir triste & 0 & 1 & 2 & 3 & 4 \\
\hline m. Por se preocupar muito com as coisas & 0 & 1 & 2 & 3 & 4 \\
\hline n. Por não sentir interesse pelas coisas & 0 & 1 & 2 & 3 & 4 \\
\hline o. Por ter enjôo ou problemas no estômago & 0 & 1 & 2 & 3 & 4 \\
\hline p. Por ter músculos doloridos & 0 & 1 & 2 & 3 & 4 \\
\hline q. Por ter dificuldade em adormecer & 0 & 1 & 2 & 3 & 4 \\
\hline r. Por ter dificuldade em respirar & 0 & 1 & 2 & 3 & 4 \\
\hline s. Por sentir de vez em quando calor ou frio & 0 & 1 & 2 & 3 & 4 \\
\hline t. Por sentir dormência ou formigamento em partes do corpo & 0 & 1 & 2 & 3 & 4 \\
\hline u. Por sentir um "nó na garganta" & 0 & 1 & 2 & 3 & 4 \\
\hline v. Por se sentir desanimado sobre o futuro & 0 & 1 & 2 & 3 & 4 \\
\hline w. Por se sentir fraco em partes do corpo & 0 & 1 & 2 & 3 & 4 \\
\hline x. Pela sensação de peso nos braços ou pernas & 0 & 1 & 2 & 3 & 4 \\
\hline y. Por ter pensamentos sobre acabar com a sua vida & 0 & 1 & 2 & 3 & 4 \\
\hline z. Por comer demais & 0 & 1 & 2 & 3 & 4 \\
\hline aa. Por acordar de madrugada & 0 & 1 & 2 & 3 & 4 \\
\hline bb. Por ter sono agitado ou perturbado & 0 & 1 & 2 & 3 & 4 \\
\hline cc. Pela sensação de que tudo é um esforço/sacrifício & 0 & 1 & 2 & 3 & 4 \\
\hline dd. Por se sentir inútil & 0 & 1 & 2 & 3 & 4 \\
\hline ee. Pela sensação de ser enganado ou iludido & 0 & 1 & 2 & 3 & 4 \\
\hline ff. Por ter sentimentos de culpa & 0 & 1 & 2 & 3 & 4 \\
\hline
\end{tabular}




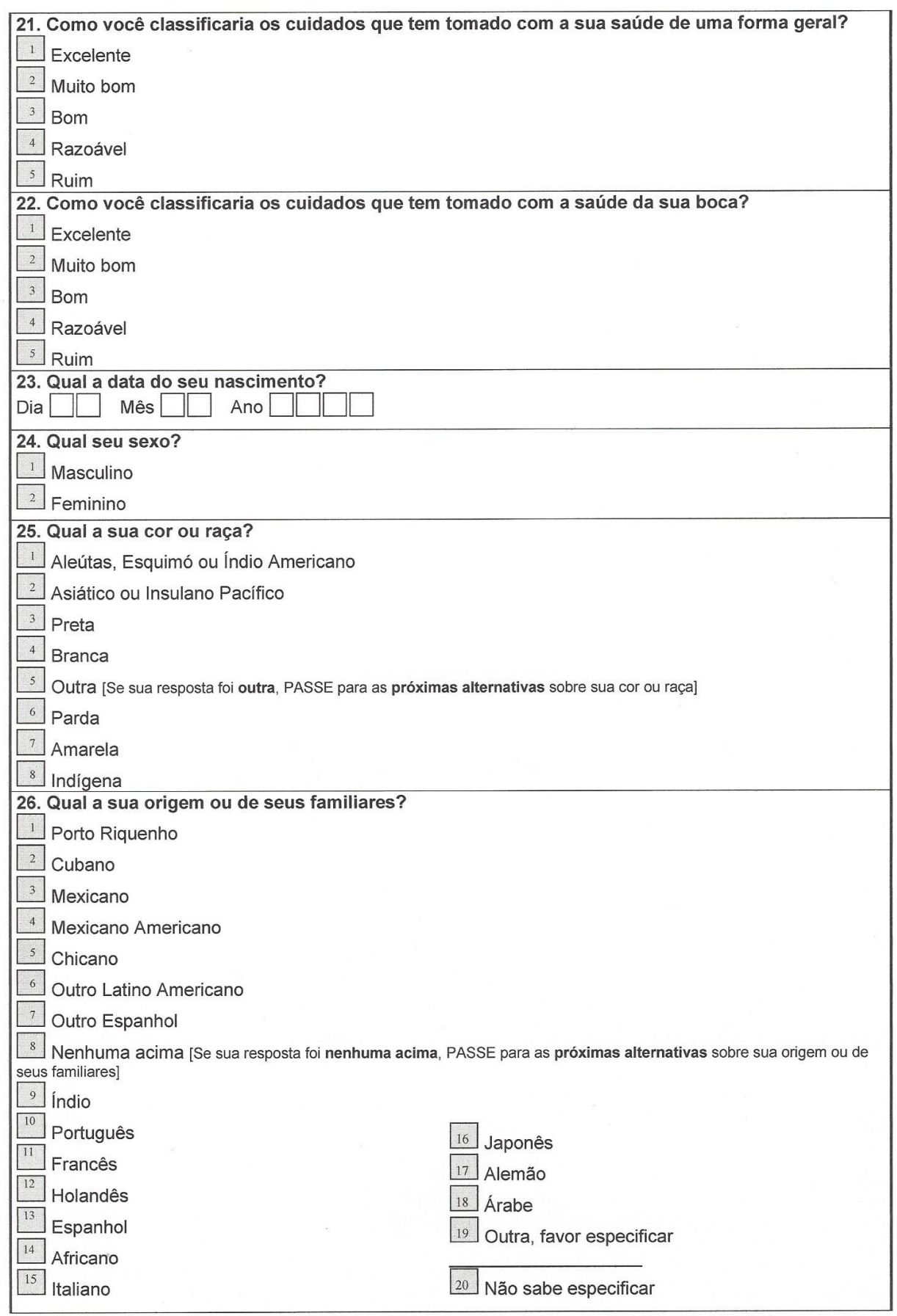




\begin{tabular}{|c|c|c|}
\hline \multicolumn{3}{|c|}{ 27. Até que ano da escola / faculdade você freqüentou? } \\
\hline Nunca freqüentei a escola & & 0 \\
\hline \multirow{4}{*}{$\begin{array}{l}\text { Ensino fundamental } \\
\text { (primário) }\end{array}$} & $1^{\text {as Série }}$ & 1 \\
\hline & $2^{\mathrm{a}}$ Série & 2 \\
\hline & $3^{a}$ Série & 3 \\
\hline & $4^{a}$ Série & 4 \\
\hline \multirow{4}{*}{$\begin{array}{l}\text { Ensino fundamental } \\
\text { (ginásio) }\end{array}$} & $5^{\text {a }}$ Série & 5 \\
\hline & $6^{a}$ Série & 6 \\
\hline & $7^{\mathrm{a}}$ Série & 7 \\
\hline & $8^{a}$ Série & 8 \\
\hline \multirow{3}{*}{$\begin{array}{l}\text { Ensino médio } \\
\text { (científico) }\end{array}$} & $1^{\circ}$ ano & 9 \\
\hline & $2^{\circ}$ ano & 10 \\
\hline & $3^{\circ}$ ano & 11 \\
\hline \multirow{6}{*}{$\begin{array}{l}\text { Ensino superior } \\
\text { (faculdade ou pós-graduação) }\end{array}$} & $1^{\circ}$ ano & 12 \\
\hline & $2^{\circ}$ ano & 13 \\
\hline & $3^{\circ}$ ano & 14 \\
\hline & $4^{\circ}$ ano & 15 \\
\hline & $5^{\circ}$ ano & 16 \\
\hline & $6^{\circ}$ ano & 17 \\
\hline
\end{tabular}

28a. Durante as 2 últimas semanas, você trabalhou no emprego ou em negócio pago ou não (não incluindo trabalho em casa)?

0 Não

1 Sim

[Se a sua resposta foi sim, PULE para a pergunta 29]

[Se a sua resposta foi não, PASSE para a próxima pergunta]

28b. Embora você não tenha trabalhado nas duas últimas semanas, você tinha um emprego ou negócio?

0 Não

1 Sim

[Se a sua resposta foi sim, PULE para a pergunta 29]

[Se a sua resposta foi não, PASSE para a próxima pergunta]

28c. Você estava procurando emprego ou afastado temporariamente do trabalho, durante as 2 últimas semanas?

1 Sim, procurando emprego

2 Sim, afastado temporariamente do trabalho

3 Sim, os dois, procurando emprego e afastado temporariamente do trabalho

4 Não

29. Qual o seu estado civil?

1 Casado (a) esposa (o) morando na mesma casa

2 Casado (a) esposa (o) não morando na mesma casa

3 Viúvo (a)

4 Divorciado (a)

5 Separado (a)

6 Nunca casei

7 Morando junto 
30. Quanto você e sua família ganharam por mês durante os últimos 12 meses? $\mathrm{R} \$$

Não preencher. Deverá ser preenchido pelo profissional

Até $1 / 4$ do salário mínimo

$\square$ De $1 / 4$ a $1 / 2$ salário mínimo

$\square$ De $1 / 2$ a 1 salário mínimo

De 1 a 2 salários mínimos

$\square$ De 2 a 3 salários mínimos

De 3 a 5 salários mínimos

De 5 a 10 salários mínimos

De 10 a 15 salários mínimos

De 15 a 20 salários mínimos

$\square$ De 20 a 30 salários mínimos

Mais de 30 salários mínimos

Sem rendimento

31. Qual o seu CEP?

$\square \square \square-\square-\square \square$

Muito Obrigado.

Agora veja se você deixou de responder alguma questão. 
EXAME CLÍNICO

1. Você tem dor no lado direito da sua face, lado esquerdo ou ambos os lados?

0 Nenhum

1 Direito

2 Esquerdo

3 Ambos

2.Você poderia apontar as áreas aonde você sente dor?

\begin{tabular}{|c|c|}
\hline Direito & Esquerdo \\
\hline 0 Nenhuma & 0 Nenhuma \\
\hline \begin{tabular}{|l|l}
1 & Articulação \\
\end{tabular} & 1 Articulação \\
\hline 2 Músculos & 2 Músculos \\
\hline \begin{tabular}{|l|l}
3 & Ambos \\
\end{tabular} & 3 Ambos \\
\hline
\end{tabular}

3. Padrão de abertura:

0 Reto

1 Desvio lateral direito (não corrigido)

2 Desvio lateral direito corrigido (" $\mathrm{S}$ ")

3 Desvio lateral esquerdo (não corrigido)

4 Desvio lateral esquerdo corrigido ("S")

5 Outro tipo

$$
\text { (Especifique) }
$$

4. Extensão de movimento vertical

Incisivo superior utilizado

a. Abertura sem auxílio sem dor $\square \square \mathrm{mm}$

b. Abertura máxima sem auxílio $\square \square \mathrm{mm}$

\begin{tabular}{|c|c|c|}
\hline & Dor Muscular & Dor Articular \\
\hline 0 & Nenhuma & 0 Nenhuma \\
\hline 1 & Direito & 1 Direito \\
\hline 2 & Esquerdo & 2 Esquerdo \\
\hline 3 & Ambos & 3 Ambos \\
\hline
\end{tabular}

c. Abertura máxima com auxílio $\square \square \mathrm{mm}$

\begin{tabular}{|c|c|c|}
\hline & Dor Muscular & Dor Articular \\
\hline 0 & Nenhuma & 0 Nenhuma \\
\hline 1 & Direito & 1 Direito \\
\hline 2 & Esquerdo & 2 Esquerdo \\
\hline 3 & Ambos & 3 Ambos \\
\hline
\end{tabular}

d. Trespasse incisal vertical $\square \square \mathrm{mm}$ 


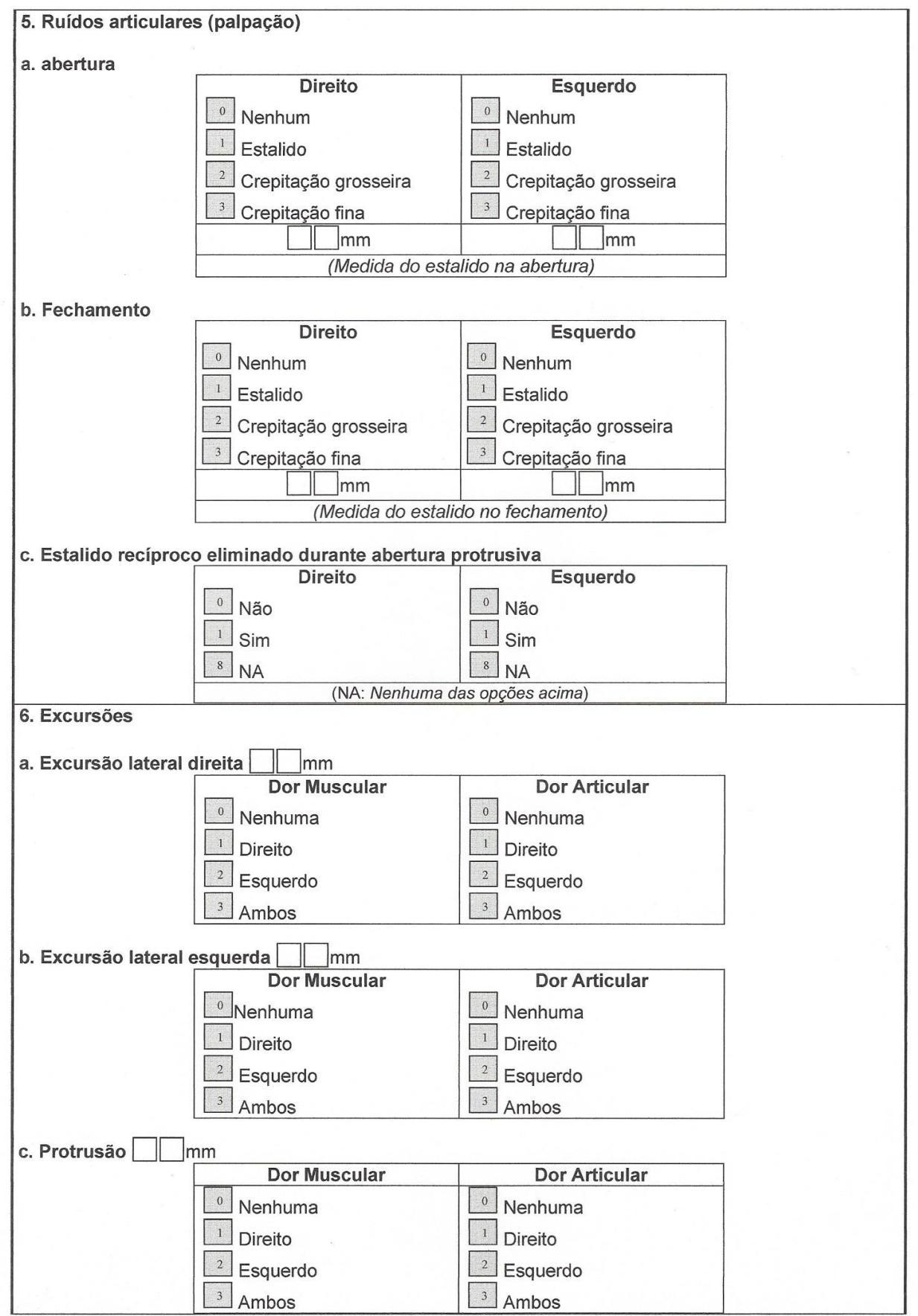




\begin{tabular}{|c|c|c|c|c|c|c|c|c|c|c|c|}
\hline \multicolumn{12}{|c|}{ d. Desvio de linha média $\square \square \mathrm{mm}$} \\
\hline \multicolumn{12}{|l|}{1 Direito } \\
\hline \multicolumn{12}{|l|}{2 Esquerdo } \\
\hline \multicolumn{12}{|l|}{8 NA } \\
\hline \multicolumn{12}{|c|}{ (NA: Nenhuma das opções acima) } \\
\hline \multicolumn{12}{|c|}{ 7. Ruídos articulares nas excursões } \\
\hline \multicolumn{12}{|l|}{ Ruídos direito } \\
\hline & Nenhum & Estalido & \multicolumn{4}{|c|}{$\begin{array}{l}\text { Crepitação } \\
\text { grosseira }\end{array}$} & \multicolumn{5}{|c|}{$\begin{array}{l}\text { Crepitação } \\
\text { fina }\end{array}$} \\
\hline 7.a Excursão Direita & 0 & 1 & \multicolumn{4}{|c|}{2} & \multicolumn{5}{|c|}{3} \\
\hline 7.b Excursão Esquerda & 0 & 1 & \multicolumn{4}{|c|}{2} & \multicolumn{5}{|c|}{3} \\
\hline 7.c Protrusão & 0 & 1 & \multicolumn{4}{|c|}{2} & \multicolumn{5}{|c|}{3} \\
\hline \multicolumn{12}{|l|}{ Ruídos esquerdo } \\
\hline & Nenhum & Estalido & \multicolumn{4}{|c|}{$\begin{array}{l}\text { Crepitação } \\
\text { grosseira }\end{array}$} & \multicolumn{5}{|c|}{$\begin{array}{l}\text { Crepitação } \\
\text { fina }\end{array}$} \\
\hline 7.d Excursão Direita & 0 & 1 & \multicolumn{4}{|c|}{2} & \multicolumn{5}{|c|}{3} \\
\hline 7.e Excursão Esquerda & 0 & 1 & \multicolumn{4}{|c|}{2} & \multicolumn{5}{|c|}{3} \\
\hline 7.f Protrusão & 0 & 1 & \multicolumn{4}{|c|}{2} & \multicolumn{5}{|c|}{3} \\
\hline \multirow{2}{*}{\multicolumn{12}{|c|}{ 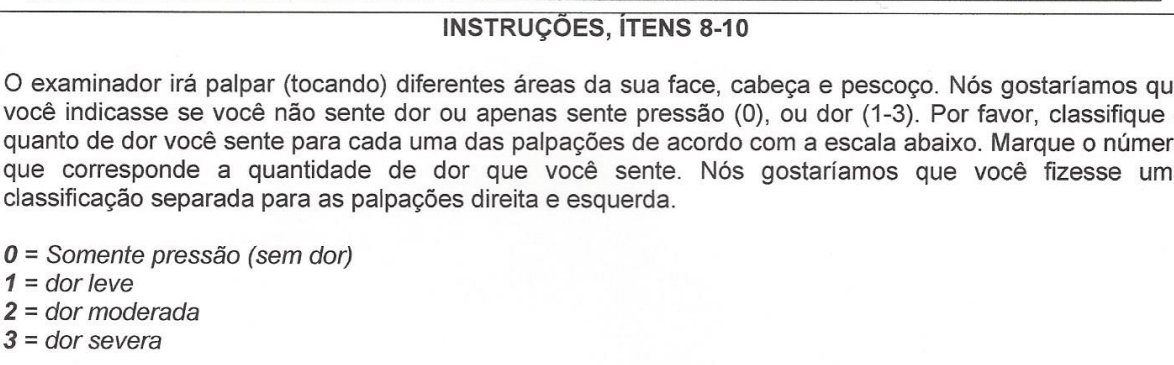 }} \\
\hline & & & & & & & & & & & \\
\hline \multicolumn{4}{|c|}{ 8. Dor muscular extraoral com palpação } & \multicolumn{4}{|c|}{ Direita } & & squ & lerd & \\
\hline $\begin{array}{l}\text { a. Temporal posterior }(1,0 \mathrm{Kg} \text {.) } \\
\text { orelhas)." }\end{array}$ & te de trás da têmpora (atrás e & liatamente ac & das & 0 & 1 & 2 & 3 & 0 & 1 & 2 & 3 \\
\hline \begin{tabular}{|l}
$\begin{array}{l}\text { b. Temporal médio }(1,0 \mathrm{Kg} .) \\
\text { sobrancelhas)." }\end{array}$ \\
\end{tabular} & da têmpora (4 a $5 \mathrm{~cm}$ late & margem late & das & 0 & 1 & 2 & 3 & 0 & 1 & 2 & 3 \\
\hline \begin{tabular}{|l} 
c. Temporal anterior $(1,0 \mathrm{Kg}$.) \\
imediatamente acima do process \\
\end{tabular} & $\begin{array}{l}\text { e anterior da têmpora (superi } \\
\text { omático)." }\end{array}$ & fossa infraten & ral e & 0 & 1 & 2 & 3 & 0 & 1 & 2 & 3 \\
\hline $\begin{array}{l}\text { d. Masseter superior }(1,0 \mathrm{Kg} .) \text { " } \\
\text { imediatamente abaixo do arco zig }\end{array}$ & $\begin{array}{l}\text { echa/ abaixo do zigoma (come } \\
\text { tico, palpando o músculo anter }\end{array}$ & $\begin{array}{l}\text { cm a frente de } \\
\text { ente)." }\end{array}$ & TM e & 0 & 1 & 2 & 3 & 0 & 1 & 2 & 3 \\
\hline $\begin{array}{l}\text { e. Masseter médio }(1,0 \mathrm{Kg} \text {.) "Bo } \\
\text { ângulo da mandibula)." } \\
\end{array}$ & hal lado da face (palpe da borc & terior descen & até 0 & 0 & 1 & 2 & 3 & 0 & 1 & 2 & 3 \\
\hline $\begin{array}{l}\text { f. Masseter inferior }(1,0 \mathrm{Kg} .) \text { "t } \\
\text { ângulo da mandibula)." }\end{array}$ & echa/ linha da mandíbula (1 & uperior e ant & or ao & 0 & 1 & 2 & 3 & 0 & 1 & 2 & 3 \\
\hline $\begin{array}{l}\text { g. Região mandibular posteri } \\
\text { "Mandíbulal região da garganta } \\
\text { posterior da mandíbula. Palpe im }\end{array}$ & $\begin{array}{l}\text { estilo-hióideo/ região posterior } \\
\text { a entre a inserção do estern } \\
\text { amente medial e posterior ao â }\end{array}$ & $\begin{array}{l}\text { digástrico) (C } \\
\text { lomastóideo } \\
\text { da mandibul }\end{array}$ & $\begin{array}{l}\text { Kg.) } \\
\text { sorda } \\
\end{array}$ & 0 & 1 & 2 & 3 & 0 & 1 & 2 & 3 \\
\hline $\begin{array}{l}\text { h. Regiäo submandibular (pter } \\
(0,5 \mathrm{Kg})^{u} \text { abaixo da mandíbula (2 }\end{array}$ & $\begin{array}{l}\text { eo medial/ supra-hióideo/ regi } \\
\text { frente do ângulo da mandíbula }\end{array}$ & nterior do dic & trico) & 0 & 1 & 2 & 3 & 0 & 1 & 2 & 3 \\
\hline 9. Dor articular com palpa & & & & & & & & & & & \\
\hline a. Polo lateral $(0,5 \mathrm{Kg}$.) "Por fora & erior ao trago e sobre a ATM)." & & & 0 & 1 & 2 & 3 & 0 & 1 & 2 & 3 \\
\hline \begin{tabular}{|l} 
b. Ligamento posterior $(0,5 \mathrm{Kg}$ \\
medial enquanto o paciente está
\end{tabular} & $\begin{array}{l}\text { "ntro do ouvido (pressione o d } \\
\text { a boca fechada)." }\end{array}$ & na direção ar & & 0 & 1 & 2 & 3 & 0 & 1 & 2 & 3 \\
\hline 10. Dor muscular intraora & m palpação & & & & & & & & & & \\
\hline $\begin{array}{l}\text { a. Área do pterigóideo lateral } \\
\text { mínimo na margem alveolar aci } \\
\text { cima e em seguida para medial }\end{array}$ & $\begin{array}{l}\text { Kg.) "Atrás dos molares sur } \\
\text { o último molar superior. Mova } \\
\text { alpar)." }\end{array}$ & $\begin{array}{l}\text { es (coloque } \\
\text { edo para dist }\end{array}$ & & 0 & 1 & 2 & 3 & 0 & 1 & 2 & 3 \\
\hline $\begin{array}{l}\text { b. Tendão do temporal }(0,5 \mathrm{Kg} \\
\text { coronóide, mova-o para cima. } \mathrm{Pa}\end{array}$ & $\begin{array}{l}\text { endão (com o dedo sobre a b } \\
\text { área mais superior do process }\end{array}$ & anterior do $p$ & & 0 & 1 & 2 & 3 & 0 & 1 & 2 & 3 \\
\hline
\end{tabular}

